\title{
Wound Healing and Dental Therapies: Repair and Regeneration
}

\author{
Michel Goldberg ${ }^{1 *}$ \\ ${ }^{1}$ Faculty of Fundamental and Biomedical Sciences, Department of Oral Biology, Paris Cité University, \\ INSERM UMR-S 1124, Paris, France
}

*Corresponding Author: Michel Goldberg, Faculty of Fundamental and Biomedical Sciences, Department of Oral Biology, Paris Cité University, INSERM UMR-S 1124, Paris, France; Tel: +33662676709;

Email: mgoldod@gmail.com

Received Date: 29-05-2020; Accepted Date: 26-06-2020; Published Date: 04-07-2020

Copyright $^{\oplus} 2020$ by Goldberg M. All rights reserved. This is an open access article distributed under the terms of the Creative Commons Attribution License, which permits unrestricted use, distribution, and reproduction in any medium, provided the original author and source are credited.

\begin{abstract}
In reaction to a wound, inflammation is associated with the healing process leading to repair or regeneration. Extracellular components (ECM) are classified into fiber-forming structural molecules (collagens I, III, V), nonfiber-forming structural molecules (including proteoglycans and glycosaminoglycans) and "matricellular proteins" (osteopontin, SPARC, CCN2, tenascin-C and Fibulin-5) that have no structural functions but modify cell-matrix interactions. Wound healing implies a sequence of phases: bleeding and formation of a clot, inflammation proceeding proliferation of epidermal cells, changes in the dermal matrix, capillary ingrowth, wound contraction and remodelling. Cellular (neutrophils, monocytes / macrophages, mast cells and stem cells) and molecular components of the wounded tissue are involved in these processes. Macrophages contribute to the removal of apoptotic bodies. Inflammation includes different forms of cell death (apoptosis, necrosis, nemosis, and autophagy). Mediators of repair and inflammation encompass growth factors (TGF- $\beta$, TGF- $\alpha$, FGF, PDGF, EGF, KGF, IGF-1, NGF, VEGF, and the serine-protease thrombin), Resident cells proliferate and migrate, closing the wound. The successive events are reflecting hormonal regulations, effects of metalloproteinases and MMPs inhibitors. Angiogenesis and the formation of granulation tissue are contributing to the end of the healing process characterized by high density of fibroblasts, granulocytes, and loosely organized collagen bundles. Either the reparative process is returning to a normal situation (wound healing), with or without the formation of a scar, or dental tissue regeneration paves the way for the future of endodontic and periodontal therapies.
\end{abstract}




\section{Keywords}

Inflammatory Cells; Extracellular Molecules; Apoptosis; Growth Factors; Wound Healing; Repair; Regeneration

\section{Introduction: The Healing of a Wound}

Wound healing involves migration, proliferation and differentiation. The cardinal signs of inflammation are heat, pain, redness, swelling, and loss of function. Wounds can be complicated, combining infection with a tissue defect. They can be classified into three groups:

1) Aseptic wounds

2) Contaminated wounds

3) Septic wounds

Epidermal healing is a combination of two processes: cell migration closing the wound, and an upregulated cell division near the wound edge. Keratinocytes Growth Factor (KGF) is produced within the dermal compartment, sinergically with the Epidermal Growth Factor (EGF). These two growth factors are determining in the repair of epidermis [1].

Inflammation participates to the formation of a fibrin plug and hemostatic events, including platelet aggregation. Interactions between cells of the innate or adaptive immune system play a major role. Inflammatory mediators orchestrate the different diseases. Monocytes undergo phenotypic changes and become macrophages as part of the inflammatory phase, occurring 48$72 \mathrm{~h}$ after injury. They continue the process of phagocytosis. Complement components, such as leukotriene B4 are involved in this phase. Macrophages are providing an abundant reservoir of potent tissue growth factors, particularly the Transforming Growth Factor- $\beta$ (TGF- $\beta$ ) as well as other mediators (TGF- $\alpha$, Heparin Binding Epidermal Growth Factor [HB-EGF], Fibroblast Growth Factor [FGF] and collagenase), activating keratinocytes, fibroblasts and endothelial cells. The last cells to enter in the late inflammatory phase are lymphocytes, attracted 72 hours after injury by the action of Interleukin-1 (IL-1), complement components and Immunoglobulin $\mathrm{G}$ ( $\mathrm{IgG})$. IL-1 regulate collagenase, which is later needed for collagen remodelling, producing of extra-cellular matrix components and their degradation. Inflammation contributes also to the different aspects that underline the diseases. Repair or regeneration may occur, after wound remodelling [2].

After the injury, fibroblasts and myofibroblasts proliferate. Fibroblasts proliferate and produce hyaluronan, fibronectin, proteoglycans and procollagen). Modelling and angiogenesis are responsive to a number of angiogenic factors, including FGF, Vascular Endothelial Growth Factor (VEGF), PDGF, angiogenin, TGF- $\alpha$ and TGF- $\beta$. 
In response to an inflammation due to a wound, a four-step process takes place:

1. Production of proteases by endothelial cells

2. Chemotaxis

3. Proliferation

4. Remodelling and differentiation, namely wound contraction. Angiogenesis is an important event implicated in tissue remodelling.

Migration is necessary for angiogenesis. Migration is dependent on the actin-rich network and regulated by the cytoskeletal intracellular organization. Regulation is achieved by three mechanisms:

1. Chemotaxis (migration towards the concentration gradient of the chemoattractive substance)

2. Mechanotaxis (migration induced by mechanical forces)

3. Haptotaxis (migration in response to a gradient of immobilized ligands)

\section{Protrusion}

With interconnected filaments (tubules, microfilaments (actin), and intermediary filaments), the cytoskeleton is anchored at cell-cell junctions and cell-extracellular matrix. Unidirectional movement of the cell is maintained through a cyclic assembly and disassembly of actin filaments in front of the leading edge.

\section{Adhesion}

Adhesion is mediated by integrins, and consequently, are required for cell motility. The cells changes their morphology from an oval- or spindle-shape to an irregular, flattened one.

Traction Contractile forces dues to interactions between myosin and actin fibres pull the cell body forwards.

\section{Epithelialization}

Migration of epithelial cells starts after wounding. A single layer of cells initially forms over the defect. Cells migrating attach to the matrix below. When the epithelial cells meet, migration stops and the basement membrane starts to form. Also, the remodelling phase follows and close the repair process.

\section{Healing by Primary and Secondary Intention}

The least complicated example of wound repair is the healing of clean wounds without loss of tissue and uninfected surgical incisions approximated by sutures. This is referred to as healing by primary intention. Numerous pathophysiological and metabolic factors local causes the inflammatory process. This is the case for oedema, ischaemia, tissue hypoxia, infection, 
necrosis and growth factor imbalance, as well as systemic causes including metabolic disease, nutritional status and general perfusion disturbances or pre-existing illness (Fig. 1).

Secondary healing implicate that the wound cannot be stitched up. There is an infectious risk. This is leading to a bigger scar, namely when there is a loss of tissue, or a chronic wound $[2,3]$.

Matricellular dermatopontin and FACIT collagens (Fibril-Associated Collagens with Interrupted Triple helix), characterize the ECM associated with wound repair. Formerly, the ECM molecules were considered as structural proteins, these molecules are now known to directly influence many aspects of cellular wound healing [4].

The extracellular components of the lesion can be divided into fiber-forming structural molecules (collagens I, III, V, with mutations in collagen IV, VII and XVII), nonfiber-forming structural molecules (proteoglycans and glycosaminoglycans including chondroitin-sulfate, dermatan-sulfate, hyaluronan, decorin, versican, and dermatopontin), and "matricellular proteins" (osteopontin, SPARC, CCN2, tenascin-C and Fibulin-5). They have no structural function but modify cell-matrix interactions.

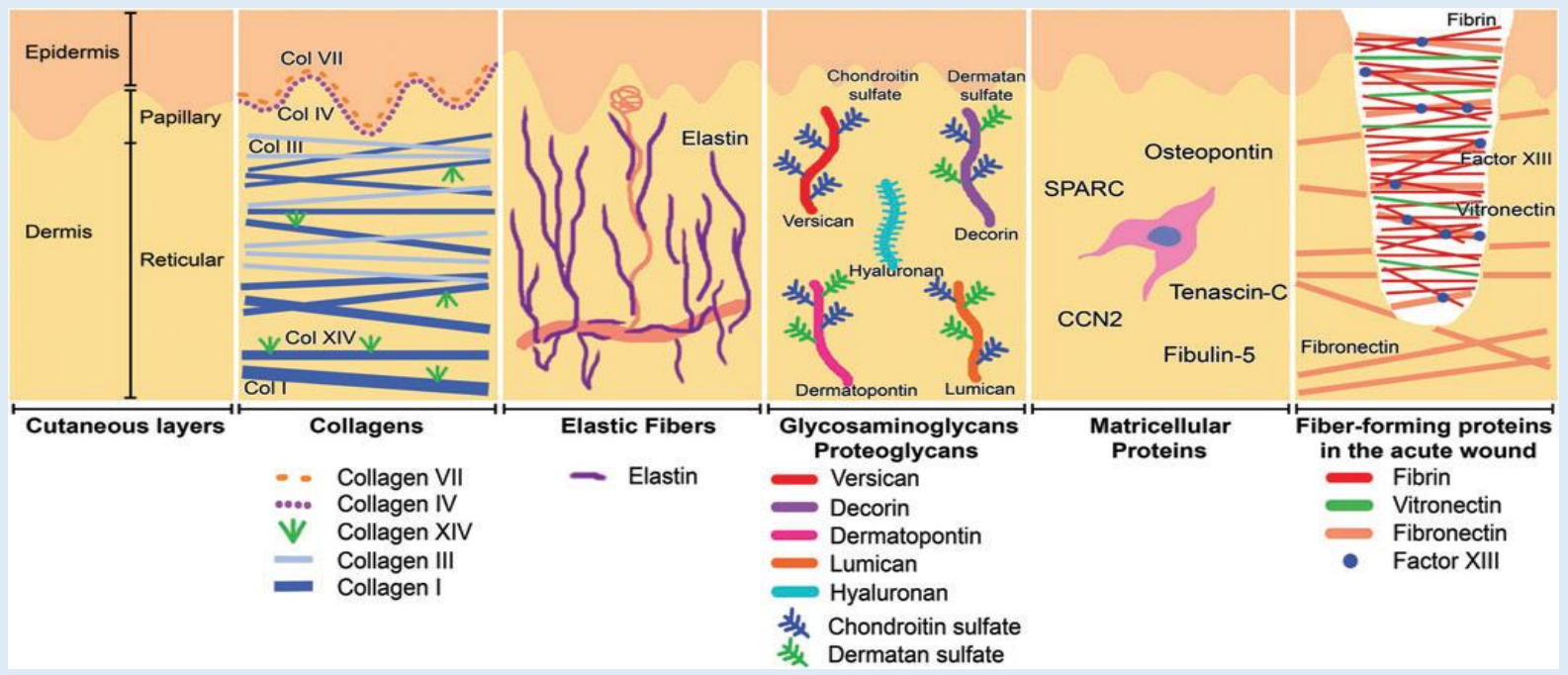

Figure 1: Extracellular components.

\section{Components of the ECM Proteins}

- Fiber forming proteins

○ Collagens

- Other fiber-forming proteins

- Fibrin, Fibronectin, Vitronectin, Elastin

- $\quad$ PGs and GAGs

- Hyaluronan, Dermatan Sulfate, Chondroitin Sulfate, Decorin, Versican

- Lumican, Dermatopontin, Biglycan, Aggrecan

- Matricellular proteins 
O Osteopontin, Secreted Protein Acidic and Rich in Cysteine (SPARC), Tenascin-C, Fibulin-5.

Fibroblasts show an increased expression of $\alpha \beta$ integrin. The fibroblasts also show a decreased expression of $\alpha \beta$ integrin, required for fibroblast migration. The pathways involving src-kinase substrate are thought to be involved in the process (Fig. 2).

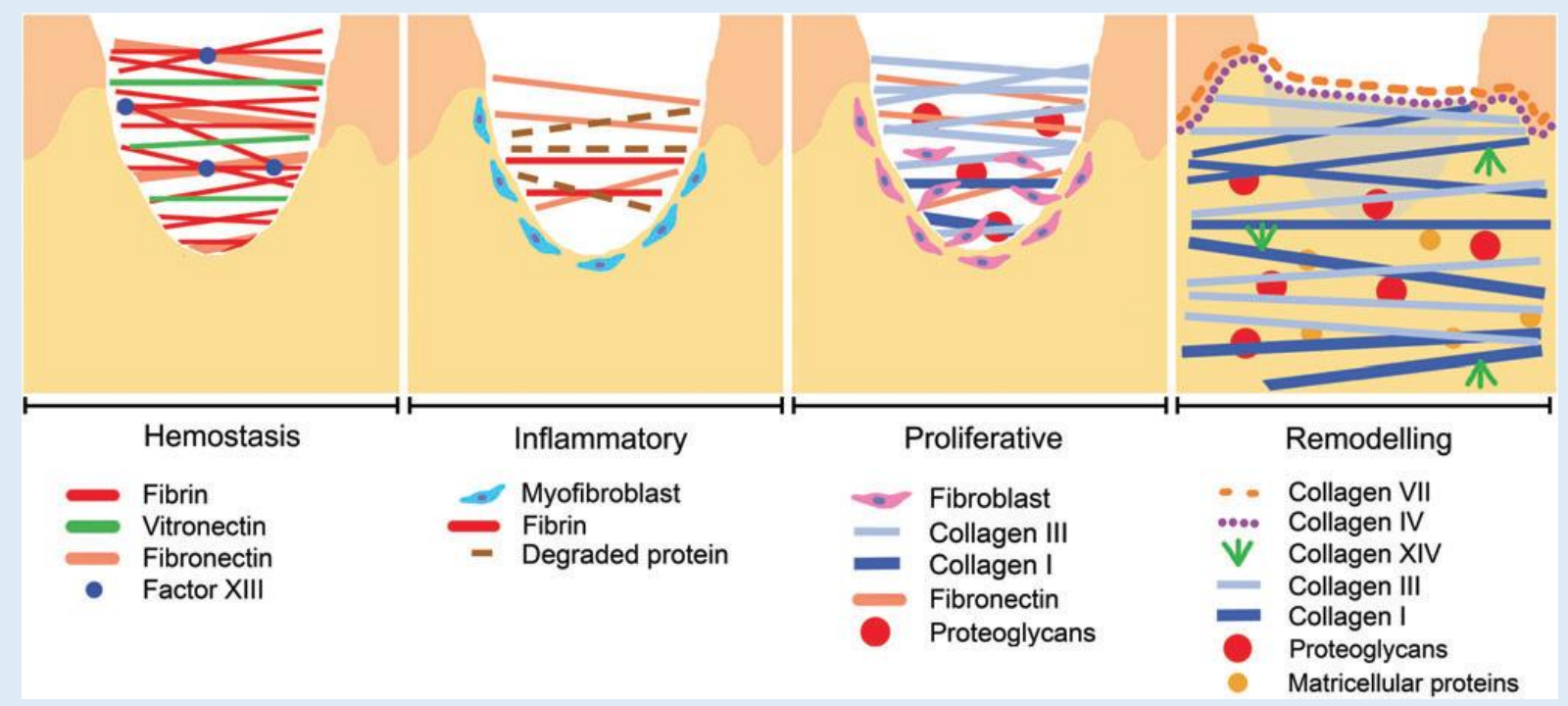

Figure 2: ECM proteins correlation with wound healing.

\section{Cell Death}

\section{Cellular Components}

Neutrophils, lymphocytes, macrophages, mast cells, and innate lymphoid cells are found within the lesion. Macrophages are highly plastic, and may inhibit or stimulate cell proliferation and tissue repair corresponding to their polarization to either pro-inflammatory (classical pathway), or pro-repair (alternative pathway) phenotypes. Langerhans and CD8-positive T-cells populate human epidermis [5].

\section{Molecular Components}

Oral lesions contains defensins (antimicrobial peptides). They stimulate keratinocyte migration. 


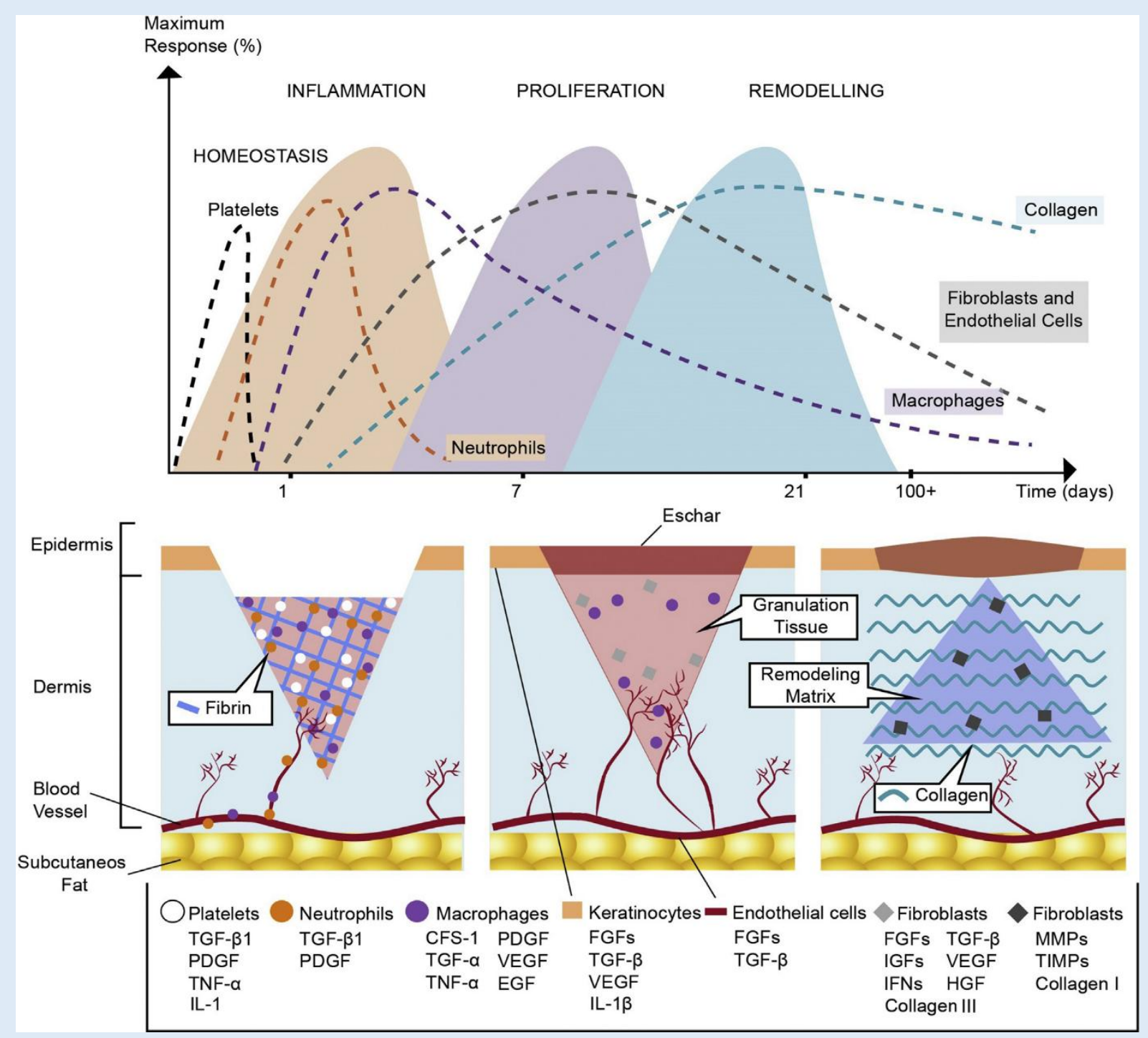

Figure 3: Skin wound healing.

\section{Cells Involved in Immuno-inflammatory Reaction and Cell-Cell Interactions in Wound Healing}

Interactions between endothelial and progenitor/stem cells are important for the vascularization of regenerating tissue [6]. Facilitating the migration of Human Umbilical Vein Endothelial Cells (HUVECs) and increasing Vascular Endothelial Growth Factor (VEGF) expression, DPSC increases early vascular network formation. This highlight the importance of the microenvironment and provide insight between HUVECs and DPSCs in relation to angiogenesis and pulp regeneration. The results emphasis the significance of creating a microenvironment that supports cellular cross-talk and cell migration [7].

Neutrophils arrive at the site of a wound in response to multiple chemotactic signals including IL-1, TNF-alpha and IL-8. In the wound, neutrophils arrive within a few minutes after injury. 
They are followed by monocytes and lymphocytes, acting through phagocytosis. In addition, neutrophils release several pro-inflammatory cytokines such as IL-1-alpha, IL-6, TNF- $\alpha$, TGF $\beta$ and PGE2. They undergo apoptosis and furthermore, they are phagocytized by macrophages. [8].

Neutrophils release a large variety of highly active antimicrobial substances and proteases (elastase, cathepsin $\mathrm{G}$, proteinase 3, urokinase-type plasminogen activator).

Following neutrophils, macrophages infiltrate the wound. Studies suggest that while macrophages may play an important role in the regulation of fibrosis and scarring, they may not be absolutely necessary for successful healing of a wound.

\section{Mast Cells}

In the early wound healing phases, mast cells enhance macrophage phagocytosis and appear to modulate neutrophil infiltration into the wound site. Mast cells release of a number of factors including Tumor Necrosis Factor (TNF), Platelet Derived Growth Factor (PDGF), Vascular Endothelial Growth Factor (VEGF) and Fibroblast Growth Factor (FGF). Mast cells are an important source of a variety of pro-inflammatory mediators and cytokines. Therefore, they are considered to be involved in tissue repair. Following injury, residential mast cells de-granulate and therefore may become less apparent.

T-cells appear in the wound site after wound closure has occurred and infections have been cleared. T-cells appear to modulate the healing response through the production of cytokines and growth factors. The healing response can be modulated. PMN are involved in the phagocytosis of infectious agents. Lymphocyte accumulation is associated with the initial appearance of MCP-1, 4 days after injury, by the chemokines (IFN- $\gamma$-inducible protein-10 and monokine induced by IFN- $\gamma$ ). Macrophages appear to be a major source for these cytokines. IFN- $\gamma$ gene deficiency leads to an accelerated healing response. With a consequent augmented TGF- $\beta 1$-mediated signalling pathway and accelerated collagen deposition. T-cells also influence the healing response by direct cell-cell interactions with resident and non-resident cells at the wound site. Interactions between the membrane-bound glycoprotein CD40 and CD40 ligand play an important role. CD40 ligand-expressing T-cells interacts with CD40expressing keratinocytes, fibroblasts, platelets, and macrophages, altering their expression profile of inflammatory mediators, and has consequent repair functions [9].

Monocytes/macrophages emigration of blood monocytes into the wound is regulated by the interaction of the very late antigen- 4 ( $\alpha 4 \beta 1$ integrin) and endothelial vascular cell adhesion molecule-1. Macrophage infiltration into the wound site is highly regulated by chemotactic factors. Monocytes extravagate from the blood vessel, become activated and differentiate into mature tissue macrophages. This transformation implies a major change in the activation 
phenotype of the macrophages. Mediators present in the microenvironment direct the activation process. Beside their immunological functions macrophages are thought to play an integral role in a successful outcome of the healing response through the synthesis of numerous potent growth factors, such as PDGF and VEGF, which promote cell proliferation and the synthesis of extracellular matrix molecules by resident cells.

\section{Stem Cells and Healing}

Overlapping phases of healing wounds, Stem Cells offer a novel option that differs dramatically from current treatment options [10]. MSCs can be deployed within scaffoldings, topically or by injection, and influence the microenvironment and the healing process in a more regenerative manner through paracrine functioning [11]. Nakashima et al., transplanted dental pulp stem cells in pulpectomized teeth, and reported that they regenerate completely the pulp (Fig. 4) [12].

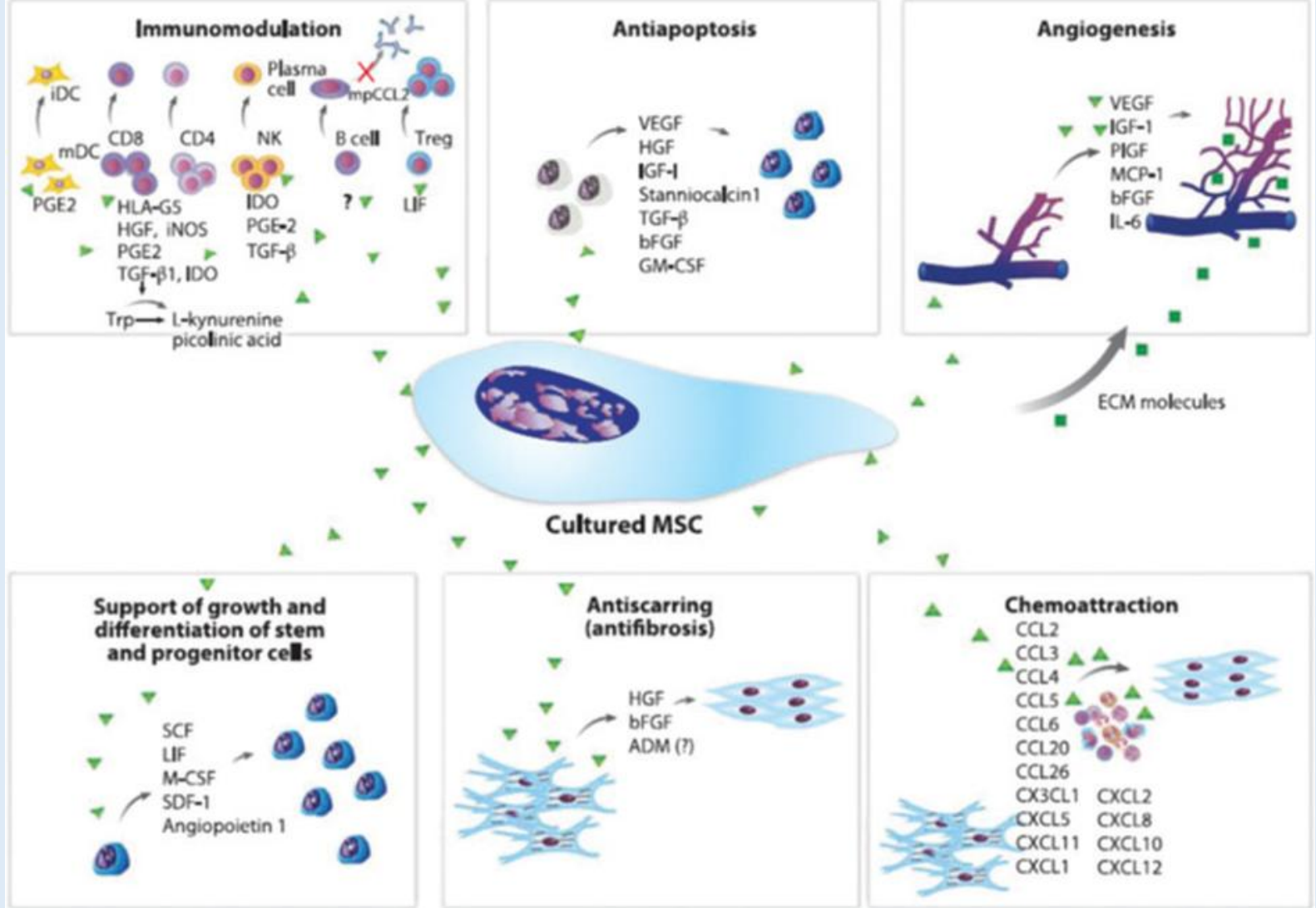

Figure 4: Paracrine effects of cultured mesenchymal stem cells.

\section{Mediators of Inflammation and Repair}

There are numerous intrinsic and extrinsic differences between the fotus and adult that may influence tissue repair. Macrophage migration inhibitory factor, is a crucial mediator of 
excessive inflammation. Similar to fotal repair, levels of TGF- $\beta$ in wounds of the elderly are markedly reduced, and this phenomenon might represent the underlying mechanism of reduced scarring observed with age.

\section{Growth Factors and Hormones}

A Growth Factor is a naturally occurring substance, capable of stimulating cellular growth, proliferation and cellular differentiation. Usually it is a protein or a steroid hormone. Growth factors are important for regulatinga variety of cellular processes promoting cell differentiation and maturation.

The localization of Platelet-Derived Growth Factor (PDGF), Transforming Growth Factor $\beta$ (TGF $\beta$ ) and basic Fibroblast Growth Factor (bFGF), display speficity. TGF $\beta$ and bFGF are present in neonatal and adult wounds, but are not detectable in the foetal wounds, while PDGF was present in foetal, neonatal, and adult wounds. This pattern correlates with the known effects in vitro of these factors, and neovascularization in the foetal wound, and the patterns of collagen deposition in both foetal and adult wounds. The results suggest that it is possible to manipulate the adult wound to produce more foetal-like, scar-less, wound healing [13].

The Platelet-Derived Growth Factor Family (PDGF) is released from degranulation platelets. PDGF has been suggested to have two major but distinct roles in wound repair: an early function to stimulate fibroblast proliferation and a later function inducing the myofibroblast phenotype.

\section{Cyclooxygenase-2 (COX-2) and Prostaglandin E2 (PGE2)}

The induction of the cyclooxygenase-2 (COX-2) enzyme, catalyses the conversion of arachidonic acid to prostaglandins. Inflammatory stimuli induce the release of arachidonic acid from membrane phospholipids, inducing the activity of phospholipases and also the production of the COX-2 enzyme, contributing to an increase in prostaglandin E2 (PGE2) and other arachidonic acid pathway [8].

\section{The Fibroblast Growth Factor Family (FGFs)}

The family of FGF consists of 22 members and FGF receptors 1-4 stimulate the proliferation of mesodermal, ectodermal and endodermal cells. The keratinocyte growth factor 7 (KGF 7) is specific for epithelial cells, whereas FGF1 and FGF2 stimulate angiogenesis.

\section{Epithelial (epidermal) Growth Factor}

The family comprises multiple mediators such as the transforming growth factor- $\alpha$, heparin binding-EGF, involved in the tissue specific proliferation/differentiation homeostasis [14].

The Epidermal Growth Factor (EGF) receptor signalling pathway regulates fundamental functions including survival, migration, and proliferation. Cultured keratinocytes display 
relevant levels of TGF- $\alpha$, HB-EGF and epiregulin are barely detectable at the transcript level. EGFR can be activated by several mechanisms under physiological and pathologic conditions. Apart from direct activation by specific ligands, heterologous ligand dependent mechanisms as demonstrated by the finding that stimulation of a number of G-protein Coupled Receptors (GPCRs) results in EGFR activation via metalloproteinase-mediated cleavage of the mature form of EGFR ligands from membrane precursors. Sites of auto phosphorylation in an activated EGFR bind a number of other signalling proteins containing phosphotyrosine-binding domains, and including phospholipase subunit of phosphatidylinositol 3-kinase. In the phosphatidyl-inositol-3-kinase-dependent pathway, the phosphorylation of the serinethreonine kinase Akt results in the phosphorylation of other proteins that improve cell survival. EGF, TGF- $\beta$ and HB-EGF exert their function via binding to the EGFR, a transmembrane protein tyrosine kinase expressed on many cell types. Consistent with the expression of the ligands at the wound site, EGFR mRNA and protein were detected in healing wounds.

\section{Connective Tissue Growth Factor}

It is produced by fibroblasts following stimulation by TGF- $\beta$ and appears to act as an autocrine growth factor. Biological effects of CTGF include proliferation, angiogenesis, migration, production of extra -cellular matrix (ECM), cell attachment and survival.

\section{Estrogens}

Two estrogen receptors, alpha and beta, have been cloned and they are expressed by fibroblasts, macrophages, endothelial and epidermal cells.

\section{Androgens}

The skin expresses the two genes encoding 5 alpha-reductase, which converts testosterone to its more active metabolite, 5 alpha-dihydrotestosterone.

\section{Vascular Endothelial Growth Factor}

The VEGF family includes VEGF -A, -B, -C, -D, -E and the Placenta Growth Factor (PLGF). They are binding to three different transmembrane tyrosine kinase receptors designated VEGFR-1, -2, -3. VEGFR-A is involved in the regulation of angiogenesis.

\section{Anglopoietins and Their Receptors}

This family is acting on the vascular endothelium. Angiopoietin-2 expression was transiently upregulated during the period of granulation tissue formation.

\section{Insulin-like Growth Factor}

IGF-I and -II stimulate mitogenesis of many different cells types. They exert an autocrine, paracrine, or/and endocrine functions manner. IGF-II binds to the mannose-6-phosphate receptor. IGF-I and PDGF enhance regeneration of periodontal defects. 


\section{Scatter Factors}

Scatter Factors (SF), also known as Plasminogen-Related Growth Factor (PRGF) encompass two members: the Hepatocyte Growth Factor (HGF/SF) and Macrophage-Stimulating Protein (MSP). They are secreted as inactive precursors and they are cleaved proteocally to produce active, disulfide-linked heterodimers.

\section{Nerve Growth Factor}

Nerve Growth Factor (NGF) is essential for the development and survival of certain sympathetic and sensory neurons in both the central and peripheral nervous systems. Surgical removal of the submandibular glands of mice retards the rate of contraction of wounds. NGF stimulates the proliferation and inhibits apoptosis of keratinocytes in vitro and enhances adherence molecule expression on human dermal microvascular endothelial cells. NGF has a potent effect on fibroblast migration and increases smooth muscle actin expression and collagen gel contraction.

\section{Transforming Growth Factor- $\beta$}

Transforming Growth Factor- $\beta$ includes TGF $\beta-1$ to -3 and Bone Morphogenetic Proteins (BMPs). Synthesized as latent precursors, they are usually secreted as a complex with TGF- $\beta$ binding protein. Proteolytic cleavage activates TGF- $\beta$ that exert their biological functions via binding to a heteromeric receptor complex, consisting of one type I and one type II receptor, both of which are serine-threonine kinases. In addition, they bind to a nonsignaling type III receptor, which functions mainly to present TGF- $\beta$ to the type II receptor. They have been shown to be mitogenic for fibroblasts. They inhibit proliferation of most other cells, including keratinocytes.

TGF- $\beta$ is released from platelets. This Growth Factor (GF) serves as a chemoattractant for neutrophils, macrophages, and fibroblasts. They further enhance TGF- $\beta 1$ levels in various cell types. Latent TGFs- $\beta$ are allowing sustained release by proteolytic enzymes. This combination of cellular sources and temporary storage ensures a continuous supply of TGF- $\beta$ throughout the repair process.

TGF- $\beta$ stimulate reepithelialisation and granulation tissue formation. The effect of TGF- $\beta$ on expression by keratinocytes after wounding, suggests that TGF- $\beta$ is a negative regulator of reepithelialisation. On the other hand, it also induces the expression of integrins, necessary for keratinocyte migration across the fibronectin-rich provisional wound matrix. Exogenous TGF$\beta$ was shown to stimulate angiogenesis, fibroblast proliferation, myofibroblast differentiation, and matrix deposition. Mice expressing a dominant-negative Type II TGF- $\beta$ receptor in the 
epidermis show accelerated reepithelialisation and reduced keratinocyte apoptosis. Impaired wound healing was seen in fibroblasts of mice lacking the TGF- $\beta$ Type II receptor.

\section{Activins}

Activins as members of the TGF $\beta$-superfamily are dimeric proteins, consisting of two $b_{A}$ subunits (activin A), and two $\beta_{B}$ subunits (activin B), or $\alpha \beta_{A}$ and $\alpha \beta_{B}$ subunit (activin $A B$ ). There is an increased expression of activin after injury. Overexpression of activin in the epidermis enhances wound repair, whereas overexpression of the activin antagonist follistatin leads to impaired wound healing.

\section{Bone Morphogenetic Proteins}

Fifteen Bone Morphogenetic Proteins (BMPs) have been identified which exert their functions by binding to heteromeric receptor complexes of a type II receptor and two different type I receptors. BMP -2, -4, -7 induce massive dermal and epidermal expression.

\section{Connective Tissue Growth Factor}

Connective tissue growth factor leads to overexpression of the family of CNN that comprises 6 different members. The Connective Tissue Growth Factor (CTGF) plays an important role in cutaneous wound repair. It is abundant at day 1 after injury and declined to basal levels within the next 5 days. A potent effect of CTGF appears to be important for granulation tissue. It promote endothelial proliferation, migration, survival, adhesion and in angiogenesis.

\section{Chemokines}

They are small, secreted proteins that play important roles in wound repair. They includes interleukins, lymphokines, and several related signaling molecules such as the tumor necrosis factor- $\alpha$ (TNF- $\alpha$ ) and interferons. Chemokines (chemotactic cytokines) are a subset of small cytokines that stimulate chemotaxis and extravasation of leukocytes. This protein family includes nearly 50 members. It is subdivided into four subfamilies, $\alpha-(\mathrm{CXC}-\alpha)$ and $\beta-(\mathrm{CC}-\beta)$ chemokines, including most of the chemokines, and two additional subfamilies, the $\mathrm{CX} 3 \mathrm{C}$ chemokines and $\mathrm{C}$-chemokines. The $\mathrm{CXC}$-receptors and the $\mathrm{CC}$-receptors recognize chemokines only in the corresponding subfamily.

\section{Macrophage}

Chemo-attractant Protein has a role in the regulation of inflammation, granulation, tissue formation, and reepithelialisation.

\section{Thymosine $\beta 4$}

Thymosine $\beta 4$, the angiogenic thymic peptide, is implicated in wound healing, and namely in angiogenesis. It increases keratinocyte migration and reepithelialisation by $42 \%$ at 4 days and 
as much as $71 \%$ by day 7 post-wounding. T $\beta 4$ stimulated keratinocytes migration (15). It was also suggested a role for $\mathrm{T} \beta 4$ in wound contraction.

\section{Pro-inflammatory Cytokines}

IL- $1 \alpha$, IL-1 $\beta$, IL-6, and TNF $\alpha$ was shown to be expressed during the inflammatory phase of healing. Polymorph nuclear and macrophages were shown to be the major source of cytokines, but expression was also observed in some resident cell types. IL-6 Knock-out Mice was shown to present severe deficits in Cutaneous Wound Repair. Signal Transducers and Activators of Transcription (STATs) transduce signals from a variety of growth factors, cytokines, and hormones. Once activated by tyrosine phosphorylation, they dimerize and translocate to the nucleus, where they bind to specific DNA elements and regulate the target gene expression.

\section{Granulocyte-Macrophage Colony Stimulating Factor}

It is mitogenic for keratinocytes and stimulate migration and proliferation of endothelial cells. Overexpression of GM-CSF in the Epidermis of Transgenic Mice accelerates wound reepithelialisation.

\section{Leptin}

It is a $16 \mathrm{kDa}$ protein, produced by adipocytes that accelerates wound repair.

\section{Bcl-2 and the Regulation of Programmed Cell Death (16) or Apoptosis}

Bcl-2 is the acronym for B-cell lymphoma/leukemia-2 gene. It regulates apoptosis and displays 4 phases shedding lights on the role of apoptosis in wound healing. Some specific cell types must be eliminated from the wound. The most frequent method of cellular down-regulation is related to apoptosis [17]. Apoptosis allows the eliminations of entire populations without tissue damage or implicated in an inflammatory response [18]. The cell evolution after cell damage involves cell death by autophagy, necrosis, pyroptosis or necroptosis.

1. Apoptosis or programed cell death is an active process, stimulated by environmental factors. Apoptosis is characterized by cell shrinkage, membrane blabbing, leading to the formation of apoptotic bodies, nuclear pyknosis, chromatin condensation, and genomic fragmentation. Apoptosis is executed by caspase proteases, especially caspase-3.

2. Autophagy is a highly regulated process involving the bulk degradation of cytoplasmic macromolecules and organelles in mammalian cells via the lysosomal system in order to maintain cellular homeostasis and survival.

3. Pyroptosis is part of the host defense system. It has been described in monocytes, macrophages and dendritic cells infected with a range of microbial pathogens.

4. Necroptosis-nemosis: This active necrosis may be executed through a mechanism termed necroptosis or programmed necrosis. Affected pulp cells die from two major processes:

Goldberg M | Volume 1; Issue 2 (2020) | JDHOR-1(2)-008 | Review Article 
apoptosis and necrosis. Fibroblasts produce a significant amount of pro-inflammatory cytokines and Cyclooxygenase-2 (COX-2). The process is characterized as programmed necrosis-like death, which is named "nemosis". Although no activation of caspase-3 has been detected in nemosis, caspase inhibitors such as the pan-caspase inhibitor Z-VADFMK and the caspase- 3 inhibitor Z-DEVD-FMK inhibited cell death by $40 \%$ and $80 \%$, respectively (Table 1 and 2).

\begin{tabular}{|l|l|}
\hline \multicolumn{1}{|c|}{ Pathways } & \multicolumn{1}{|c|}{ Molecular systems are activated by: } \\
\hline First, the extrinsic pathway is activated by & $>$ Bcl-2 family proteins (Bax, Bad, Bak, Bid, Bcl-XS) \\
\cline { 2 - 2 } internal surveillance mechanism. Bax and & $>$ Initiator caspases (2, 8, 9 and 10) \\
Bak forming a pore that release & $>$ Cellular survival mechanisms are activated by \\
\cline { 2 - 2 } cytochrome c activate the intrinsic & $>$ Bcl-2 family proteins (Bcl-2, Bcl-XL, Bcl-w). \\
\cline { 2 - 2 } pathway. The release of cytochrome c & $>$ p53 \\
induces the formation of apoptosome, & \\
which bind and activates procaspase 9 that & \\
activates procaspase 9, Caspase-9 leads to & \\
death of the cell. & \\
\hline Second, the first step is followed by an & \\
effector phase. Mitochondries release & \\
molecules into the cytosol. The cell can & \\
survive if the cell is exposed to survival & \\
factor. Cytochrome C binds to the & \\
Apoptosis Protease Activating Factor & \\
(APAF-1) Smac/Diablo, a caspase & \\
coactivator. Endonuclease G causes DNA & \\
fragmentation. AIF (Apoptosis Inducing & \\
Factor) controls the nucleus for chromatin & \\
condensation & \\
\hline The third stage is the degradation phase: & \\
The rescue of the cells is no more possible, & \\
whereas during the 1st and second phases, & \\
cell dead is reversible. & \\
\hline Fourth stage : the cell is fragmented into & \\
membrane-enclosed vesicles (apoptotic & \\
bodies). & \\
\hline
\end{tabular}

Table 1: The successive steps of apoptosis. 
In general, the Hedgehog (Hh) signalling pathway regulates tissue construction (during development) and reconstruction (in adults). This is accomplished via Hh-dependent autocrine/ paracrine mechanisms that control the size and localization of Hh-responsive cell populations. Some of the earliest signals include various injury-related pro-inflammatory cytokines (e.g., tumor necrosis factor- $\alpha$, lymphotoxin- $\beta$, interferon- $\gamma$ ) and growth factors [e.g., Hepatocyte Growth Factor (HGF), Insulin-Like Growth Factor (IGF), Epidermal Growth Factor(EGF), Platelet-Derived Growth Factor-BB (PDGF-BB), and Transforming Growth Factor- $\beta 1$ (TGF$\beta 1)]$. All these GF are released by the dying cells, resident and infiltrating immune cells, myofibroblasts, and the surviving liver epithelial cells. To repair damage, many adult tissues reactivate embryonic mechanisms, including $\mathrm{Hh}$ pathway activation, that regulate tissue construction during development.

\section{Vitamin D}

The vitamin D Receptor (VDR) is a member of the family of nuclear hormone receptors. This ligand-activated transcription factor belongs to a subfamily that also includes the triiodothyronine, retinoid-X and retinoic acid receptors. The biological effects of $1,25(\mathrm{OH})_{2} \mathrm{D}$ are mediated by a nuclear receptor, the VDR. The VDR belongs to the subfamily of nuclear hormone receptors, which also includes the retinoic acid receptors, retinoid $\mathrm{X}$ receptors, and thyroid hormone receptors. The transcriptional activity of the VDR is modulated by posttranslational modifications as well as by association with nuclear receptor coactivators [19]. In the absence of Interleukin-10, the wound closure is accelerated [20].

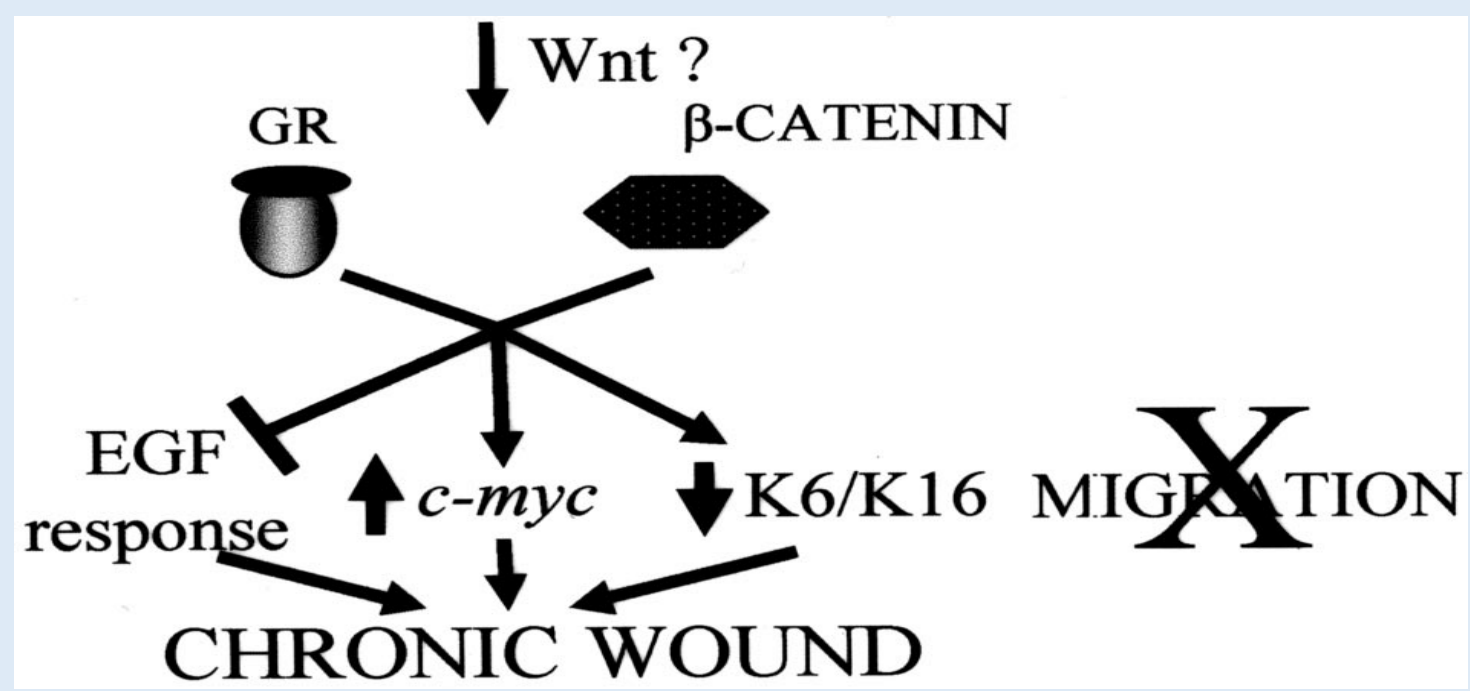

Figure 5: Roles of $\beta$-catenin and c-myc in the inhibition of epithelialization and wound healing [21].

\section{Roles of $\beta$-catenin and c-myc}


The $\beta$-catenin, c-myc, and keratins (K6 and K16), play important roles in the development of chronic wounds. The stabilization of nuclear $\beta$-catenin inhibited wound healing and keratinocyte migration by blocking epidermal growth factor response, inducing c-myc and repressing the K6/K16 keratins as cytoskeletal components that are important for cell migration. These keratins are acting as co-repressors of glucocorticoid receptor monomers. This raises the question of the role of its activator, $\beta$-catenin, in inhibition of wound healing and keratinocyte migration. $\beta$-catenin and c-myc are identified as molecular inhibitors of wound healing (Fig. 5-7).

Nemosis Process

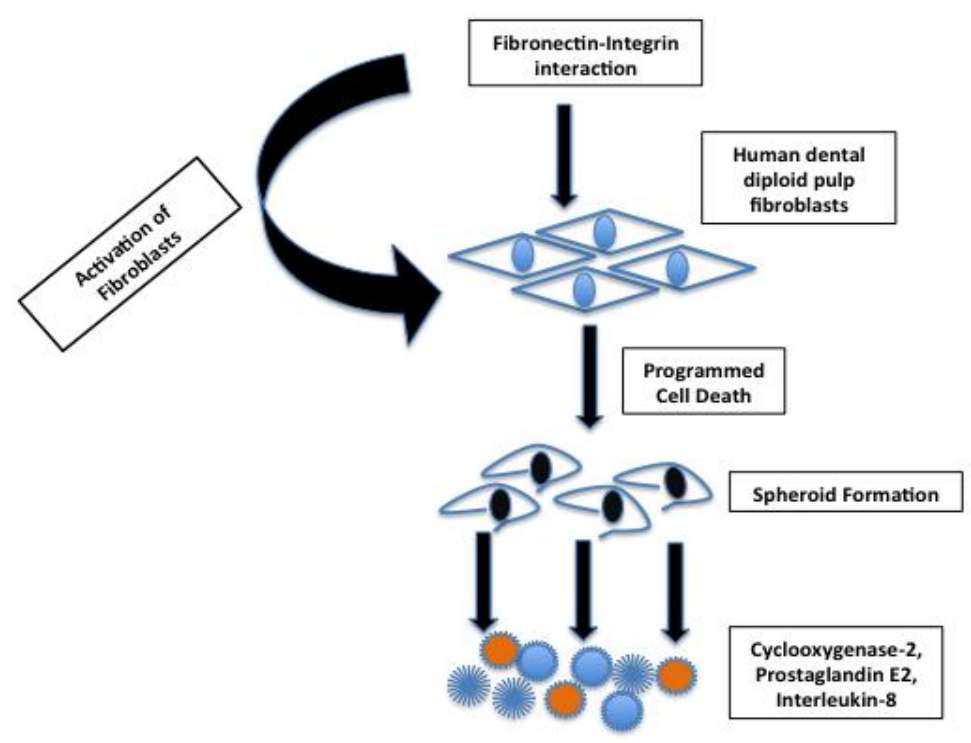

Figure 6: Nemosis: cells release COX-2, prostaglandins E2 and IL-8. Caspase protease-3 is detected in nemosis. 


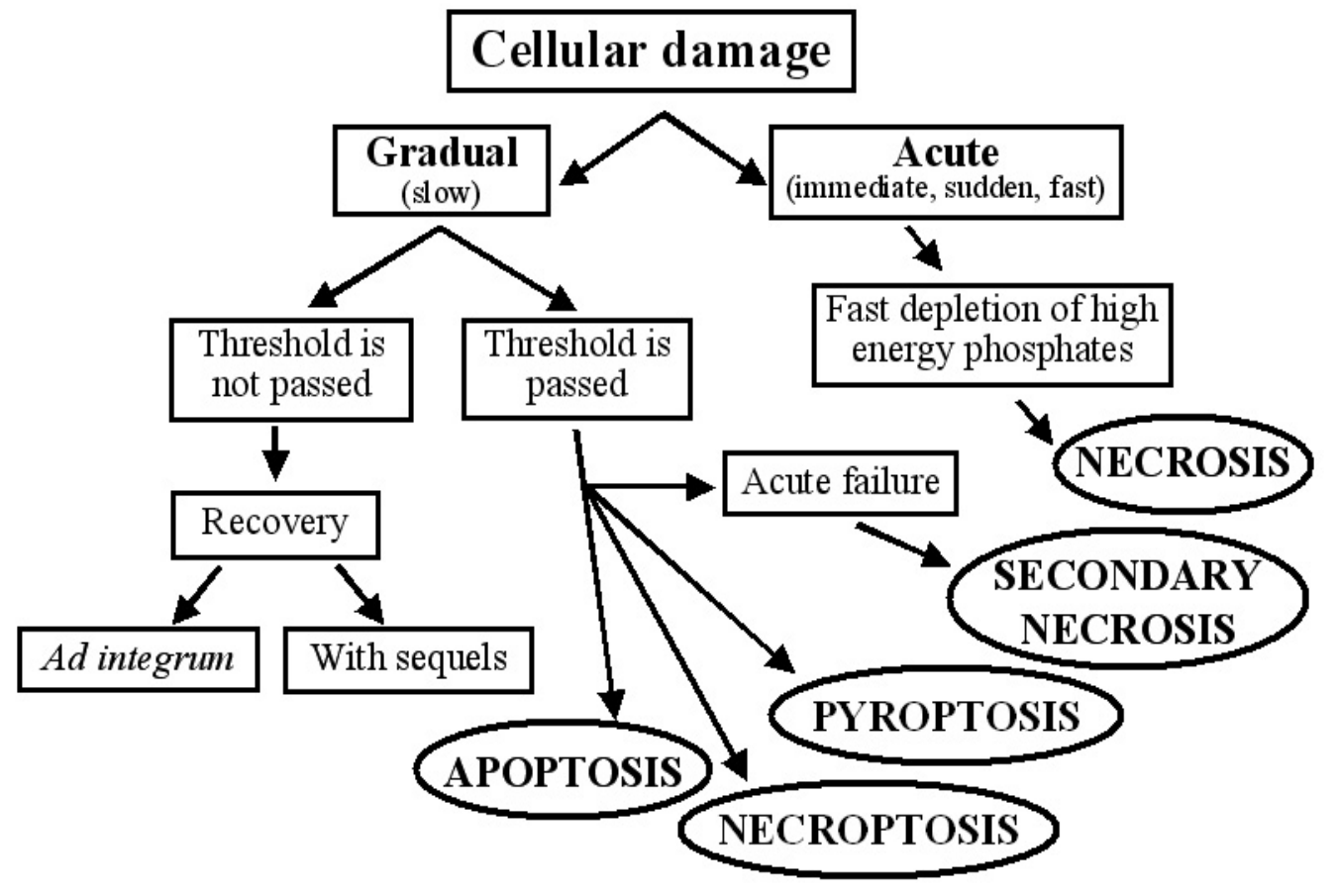

Figure 7: Cell evolution after cell damage.

\section{Wound Healing (Repair)}

- A cascade of events leading to the repair of wounds involves six phases:

1. Rapid homeostasis

2. Inflammation

3. Mesenchymal cell differentiation, proliferation and migration

4. Angiogenesis

5. Re-epithelialization

6. Remodelling of the tissue [24]

- This sequence was also simplified and classified into three phases:

1. Re-epithelialization

2. Formation of granular tissue

3. Contraction of the underlying wound connecting tissue [6]

- Another classification refers to 3 phases in wound healing:

1. Inflammation

2. Proliferation

3. Maturation $(25,26)$

The different steps of wound repair are summarized in tables 3 and 4. 


\begin{tabular}{|l|l|l|}
\hline Mild inflammation & >pulp healing & >pulp regeneration \\
\hline Severe inflammation & $\begin{array}{l}\text { > Dendritic cells } \\
\text { Histiocytes/macrophages } \\
\text { T-lymphocytes } \\
\text { Latent or dormant pulp } \\
\text { stem cell progenitors }\end{array}$ & $>$ pulp repair \\
\hline & Necrosis & $\begin{array}{l}\text { Loss of protein functions \& } \\
\text { plasma membrane integrity. } \\
\text { Coagulation necrosis } \\
\text { Pyroptotic cell death }\end{array}$ \\
\hline & $\begin{array}{l}\text { Apoptotic caspases } \\
\text { Inflammatory caspases }\end{array}$ & $\begin{array}{l}\text { Programed necrosis-like cell } \\
\text { death }\end{array}$ \\
\hline & Nemosis & $\begin{array}{l}\text { Pro-inflammatory cytokines } \\
\text { and cyclooxygenase-2. } \\
\text { Does Human Dental Pulp } \\
\text { Fibroblasts (HDPFs) leads to } \\
\text { spheroid formation: release } \\
\text { of cyclooxygenase-2 and } \\
\text { Prostaglandin E2 }\end{array}$ \\
\hline & & \multicolumn{2}{|l}{} \\
\hline
\end{tabular}

Table 2: Mild and severe inflammation: apoptosis, autophagy, pyroptosis, nemesis. Apoptosis is characterized by the presence of C-jun $\mathrm{N}$-terminal kinase (JNK), Heath-shock proteins (HSPs) inside the dental pulp, but not in odontoblasts and in the Höhl cells layer.

\begin{tabular}{|l|}
\hline \multicolumn{1}{|c|}{ Different Phases } \\
\hline The first phase of hemostasis begins immediately after wounding, with vascular constriction \\
and fibrin clot formation. This first phase and the inflammation phase occurs through days 4 \\
to 6. \\
\hline The second phase (inflammation phase) is characterized by the sequential infiltration of \\
neutrophils, macrophages, lymphocytes, keratinocytes, fibroblasts and endothelial cells that \\
are involved in this inflammatory process Neutrophils and then macrophages and mast cells \\
emigrate from the nearby tissues, and from the circulation, macrophages, T-lymphocytes \\
and keratinocytes are also implicated the inflammatory response \\
\hline The proliferation phase (3d phase) overlaps with the inflammatory phase. Movements of \\
epidermal cells are rolling or sliding over one another [26]. From day 4 through 14, \\
fibroblasts produce collagen. This phase includes epithelialisation, angiogenesis, and \\
collagen deposition. \\
\hline The remodeling phase (4 ${ }^{\text {th }}$ phase) implies granulation tissue formation, vascular and collagen \\
remodeling [27].
\end{tabular}

Table 3: Pathway explaining the process.

\begin{tabular}{|l|l|}
\hline Phase & Cellular and Bio-physiologic Events \\
\hline \multirow{2}{*}{ Hemostasis } & Vascular constriction \\
\cline { 2 - 2 } & Platelet aggregation, degranulation, and fibrin \\
\hline
\end{tabular}

Goldberg M | Volume 1; Issue 2 (2020) | JDHOR-1(2)-008 | Review Article

Citation: Goldberg M. Wound Healing and Dental Therapies: Repair and Regeneration. J Dental Health Oral Res. 2020;1(2):1-43. 


\begin{tabular}{|l|l|}
\hline Inflammation & Neutrophil infiltration \\
\cline { 2 - 2 } & Monocyte infiltration and differentiation to macrophage \\
\cline { 2 - 2 } & Lymphocyte infiltration \\
\hline Proliferation & Re-epithelialization \\
\cline { 2 - 2 } & Angiogenesis \\
\cline { 2 - 2 } & Collagen synthesis \\
\cline { 2 - 2 } & ECM formation \\
\hline Remodelling & Collagen remodelling \\
\cline { 2 - 2 } & Vascular maturation and regression \\
\hline
\end{tabular}

Table 4: Normal wound-healing process.

\section{ECM (Extracellular Matrix) and Wound Healing}

Inflammatory cytokines include Epidermal Growth Factor (EGF), Fibroblast Growth Factor (FGF), IFN, KGF, PDGF, Vascular Endothelial Growth Factor (VEGF), Granulocyte Macrophage Colony Stimulating Factor (GM-CSF), TGF $\alpha$ and $\beta$ thromboxane A2, and the tumor necrosis factor- $\alpha$ family (TNF) [28]. All of them are implicated in wound healing. The repair process implicates:

Local factors: Ischiemia, infection, the presence of foreign bodies, edema/elevated tissue pressure.

Systemic factors: Diabetes mellitus, hypothyroidism, hypothermia and pain, major trauma and burns, sepsis,

Interactions between the ECM and Growth Factors have been recognized [29]. This is the case for HS binding to FGF-2, Vascular Endothelial Growth Factor-Induced Angiogenesis (VEGF), platelet-derived growth factor (PDGF). Tenascin-C and laminin bind to EGF receptors. Growth Factor such as TGF $\beta$ molecules. These interactions are bidirectional.

\section{MMPs and Their Inhibitors are Regulators of Wound Healing}

Metallo-proteinases are endopeptidases that utilize $\mathrm{Zn}^{2+}$ or $\mathrm{Ca}^{2+}$ in their active site. They include the metzincin family of enzymes that comprise serralysins, astacins, adamalysins (a disintegrin and metalloproteinase domain or ADAMs), and matrixins (matrix metalloproteinases or MMPs). MMPs comprise 25 members. The established functions for MMPs include ECM cleavage of growth factor receptors, shedding of cell adhesion molecules, and activation of other MMPs, which display non-catabolic functions. ADAMs contain a distintegrin or integrin-binding domain, and a metalloproteinase domain that is similar to the conserved $\mathrm{Zn}^{2+}$-binding catalytic domain of MMPs. They are transmembrane proteases and their primary function is the cleavage of extracellular domains of membrane proteins, a process 
termed ectodomain shedding. MMP-9 and MMP-13 play roles in keratinocytes migration, angiogenesis and contraction [30,31].

Among the endogenous inhibitors of MMPs, the tissue inhibitors of MMPs (TIMPs) are found, including four family members, TIMP-1, to -4 . TIMPs inhibit MMPs in a 1:1 inhibitor to enzyme ratio, through interaction of the N-terminal domain of the TIMP molecule with the active site of the MMP. Other proteins can inhibit metalloproteinase activity. The list of these inhibitors includes the $\alpha 2$-macroglobulin, a primary inhibitor of metalloproteinases in body fluids, such as Reversion-Inducing Cysteine-Rich Protein with Kazal motifs (RECK), the only known membrane-bound MMP inhibitor.

Once the cells at the wound edge begin their migration, the epithelial cells start to proliferate until a new epithelium covers the damaged tissue. The epithelial cells do not become mesenchymal cells, they remain epithelial cells that are programmed and respond in manner that is highly conserved.

A few days after the wound, a new stromal tissue called granulation tissue is formed. This involves the proliferation of fibroblasts and the subsequent migration of fibroblasts into the damaged area. Fibroblasts produce ECM structural proteins and lay down a provisional, fibronectin-rich matrix. Formation of granulation tissue requires also the formation of new blood vessels. Angiogenic signals are released from both macrophages, injured epithelial, and endothelial cells. The final phase of wound healing is the resolution of the wound, which involves ECM remodeling and contraction. Contraction occurs after the formation of the granulation tissue and requires the fibroblasts to assume a myofibroblast phenotype.

The epithelial-derived MMPs regulate the trans-epithelial migration of leukocytes and the activity and compartmentalization of chemokines. $\mathrm{CC}$ chemokines are divided into subfamilies based on their amino (N)-terminal cysteine residues and have distinct roles in attracting the influx of specific types of leukocytes. The CC-chemokines have a significant role in monocyte chemotaxis. The other subfamily, the $\mathrm{CXC}$ chemokines, primarily regulate neutrophil chemotaxis and as their designation implies that they have an extra amino acid residue between the first two $\mathrm{N}$-terminal cysteines.

One major event is the re-epithelialization, which is the re-growth of epithelia over the denuded surface. Re-epithelialization requires the cells at the wound margin to lose their cell-cell and cell-ECM contacts and transmigrate across the wound. As keratinocytes migrate, they encounter a dermal matrix rich in type I collagen, and ligation to this ECM component via the $\alpha 2 \beta 1$ integrin stimulates the expression of MMP1. MMP1 facilitates keratinocyte migration over the dermal matrix by decreasing the affinity of collagen-integrin contacts. MMP7 regulates re-epithelialization by cleavage of the E-cadherin within the adherens junctions. MMP7, however, may not be the only MMP involved in cleaving cell junctional proteins. MMP28 (Epilysin) is expressed by proliferating keratinocytes and this MMP is not expressed by migrating keratinocytes. This suggests a possible role in restructuring the basement membrane or cleaving cellular adhesion molecules and providing further cells for the migrating front. 
MMP9, or gelatinase B, after injury stimulate keratinocyte migration. The growth factors Epidermal Growth Factor (EGF) and Hepatocyte Growth Factor (HGF). It appears also that MMP14 is involved in the regulation of epithelial cell proliferation. The repair phase of wound healing is involved in multiple cellular processes including cell migration, proliferation, differentiation, and death. Although MMPs are expressed during all of these successive processes, the mechanisms through which these proteinases function are better understand, it has been suggested that both MMP2 and 9 may have inhibitory effects on cell proliferation [32].

\section{Role of MMPs in Wound Resolution}

Wound healing is showered in mice lacking MMP3 (stromelysin-1). Defective wound contraction was observed in these mice compared to their wild type counterparts. Thus, the decreased wound contraction resulted in greater distance for epithelial cells to migrate. The degradation of the ECM was originally thought to be the primary function of MMPs. It is now believed that the major role of most MMPs is to process bioactive molecules such as growth factors, cytokines and chemokines, as well as their respective receptors, The ability to degrade ECM proteins has been demonstrated for some members of the MMP family using gain- or loss-of-function approaches. It seems plausible that they have a key role in collagen remodelling during wound resolution.

\section{MMPs Inhibitors in Inflammation}

One of the predominant cytokines involved in acute inflammation is TNF $\alpha$, activated via cleavage by the Converting Enzyme (TACE) or ADAM17. One effect that TNF $\alpha$ exercise on inflammatory cells is that it stimulates expression of MMP9 through activation of the NFK B and p38 MAP kinase pathways. TIMP3 is not the only metalloproteinase inhibitor that may function during inflammation. TIMP1 exerts an anti-apoptotic effect on cytokine-stimulated endothelial cells through activation of the phosphatidylinositol-3-kinase- Akt pathway.

\section{MMPs Inhibitors in Wound Repair \& Resolution}

Both collagen and fibronectin remodelling are altered in the absence of TIMP3. It provides further support that TIMP3 is able to inhibit metalloproteinases. The alteration of metalloproteinases or their inhibitors leads to inappropriate remodelling of the ECM. Metalloproteinase cleavage of signalling molecules and namely ECM proteins, occurs during the inflammatory phase, where MMPs are capable of regulating both chemokine activity and the establishment of chemotactic gradients. Degradation of cell adhesion molecules by MMPs is also necessary during the repair phase, where MMP $1,7,9$, and 10 are required for cell migration, while the addition of a synthetic metalloproteinase inhibitor leads to impaired cell migration. 


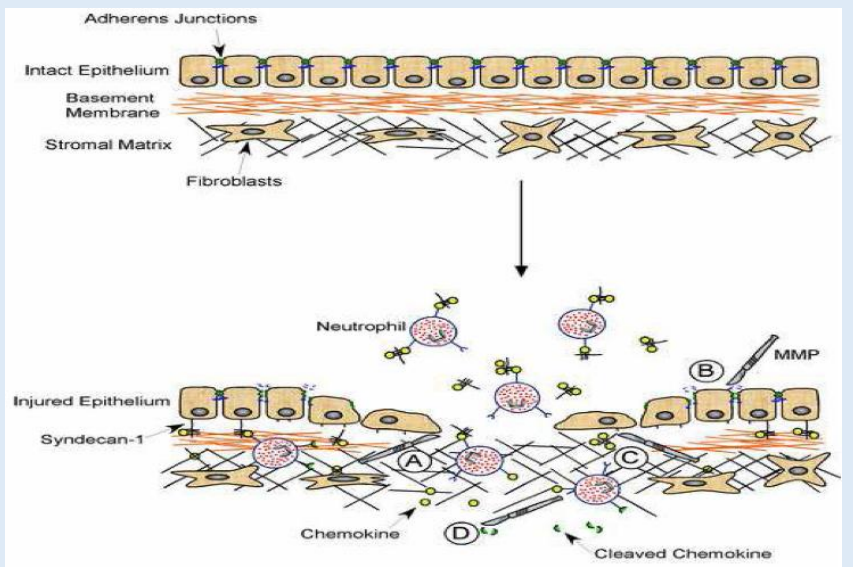

Figure 8: MMPs functions and/ or facilitation of epithelial cells proliferation. The consequences of chemokines are shown here [30].

\section{Regeneration of Dental and Periodontal Wounded Tissue}

\section{Bone Regeneration}

Bone regeneration is a complex, well-orchestrated physiological process of bone formation, observed during normal fracture healing. There are also complex clinical conditions in which bone regeneration is required in large quantity. This is the case for reconstruction of large bone defects created by trauma, infection, tumour resection and skeletal abnormalities [32]. The majority of bony injuries heal without the formation of scar tissue, and bone is regenerated with its pre-existing properties. The newly formed bone is undistinguishable from the adjacent uninjured bone. There are other conditions in orthopaedic and in oral and maxillofacial surgery in which bone regeneration is required in large quantity, such as for skeletal reconstruction of large bone defects, including avascular necrosis and osteoporosis.

BMPs have been the most extensively studied, as they are potent multi-functional osteoinductive factors. They belong to the TGF- $\beta$ superfamily and induce the mitogenesis of Mesenchymal Stem Cells (MSCs) and other osteoprogenitors, and their differentiation towards osteoblasts. Since the discovery of BMPs, experimental and clinical trials have supported the safety and efficacy of their use as osteoinductive bone-graft substitutes for bone regeneration. BMPs signal through serine/threonine kinase receptors, composed of type I and II subtypes. Three type I receptors have been shown to bind BMP ligands, type IA and IB BMP receptors (BMPR-IA or ALK-3 and BMPR-IB or ALK-6) and type IA activin receptor (ActR-IA or ALK-2) [33].

BMP-2 and BMP-7 have been licensed for clinical use. These two molecules have been used in a variety of clinical conditions including non-union, open fractures, joint fusions, aseptic bone necrosis and critical bone defects. Other GF have been employed in in order to regenerate bone, including PDGF, TGF- $\beta$, IGF-1, VEGF and FGF. Using a resorbable scaffold (coral) 
with regeneration-competent cells (marrow-stromal cells - MSC) large bone defects were recovering despite the large size of the wound [34].

Antibodies to CAP immunostained only cementum and no other periodontal components or other tissues of the body was labeled. Investigations indicate that the periodontal ligament may be one source of cementoblast progenitors in adult humans. Bone matrix had a lamellar structure, and this is not the case for cementum whitch contains typically unorganized bundle of collagen fibers. In addition, cementocytes were positive for fibromodulin and lumican, whereas osteocytes within a bone matrix were negative. This indicate that human cementum cells are phenotypically distinct from bone cells $[35,36]$.

\section{Gingival Wound Healing}

Integrins are implicated in cell adhesion and mediate information transfer. Integrins are composed of a single and a single $\beta$ subunit that are non-covalently linked to each other. At least 17 different $\alpha$ and $8 \beta$ subunits are currently known. These subunits combine to form more than 23 different cell surface receptors that have distinct ligand-binding specificities. Both $\alpha$ and $\beta$ subunits are transmembrane glycoproteins who cooperate in integrin binding to ligands [37]. Ligand binding causes clustering of the receptors, which leads to cytoskeletal organization and signalling. Integrin associated protein, transmembrane-4 superfamily, growth factor receptors and urokinase-type plasminogen activator receptor appear to have a regulatory function on integrins. Growth factor receptors accumulate in the same structures as integrins and regulate integrin functions. Integrins $\alpha v \beta 1$ and $\alpha v \beta 6$ can also bind growth factors such as TGF- $\beta 1$ through its latency-activated peptide that contains an Arg-Gly-Asp (RGD) peptide sequence. Classification system for periodontal diseases was presented in 1999, but has to be revisited periodically $[38,39]$.
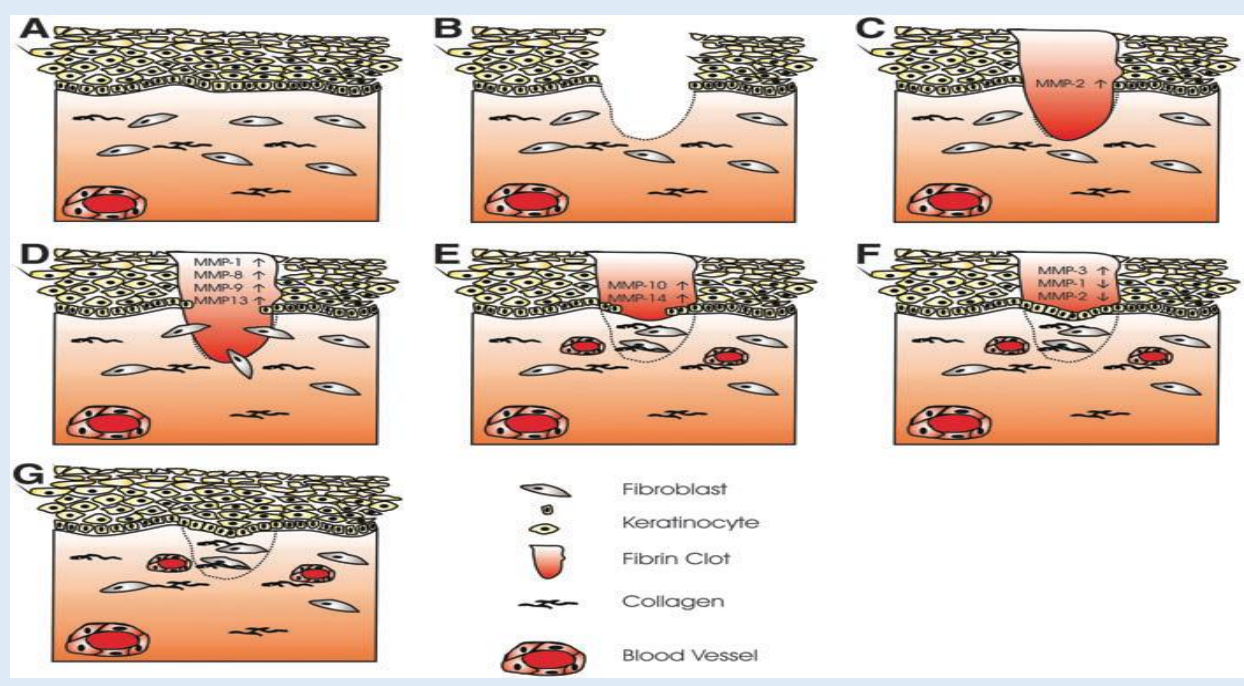

Figure 9: Wound healing after a gingival lesion [40]. 


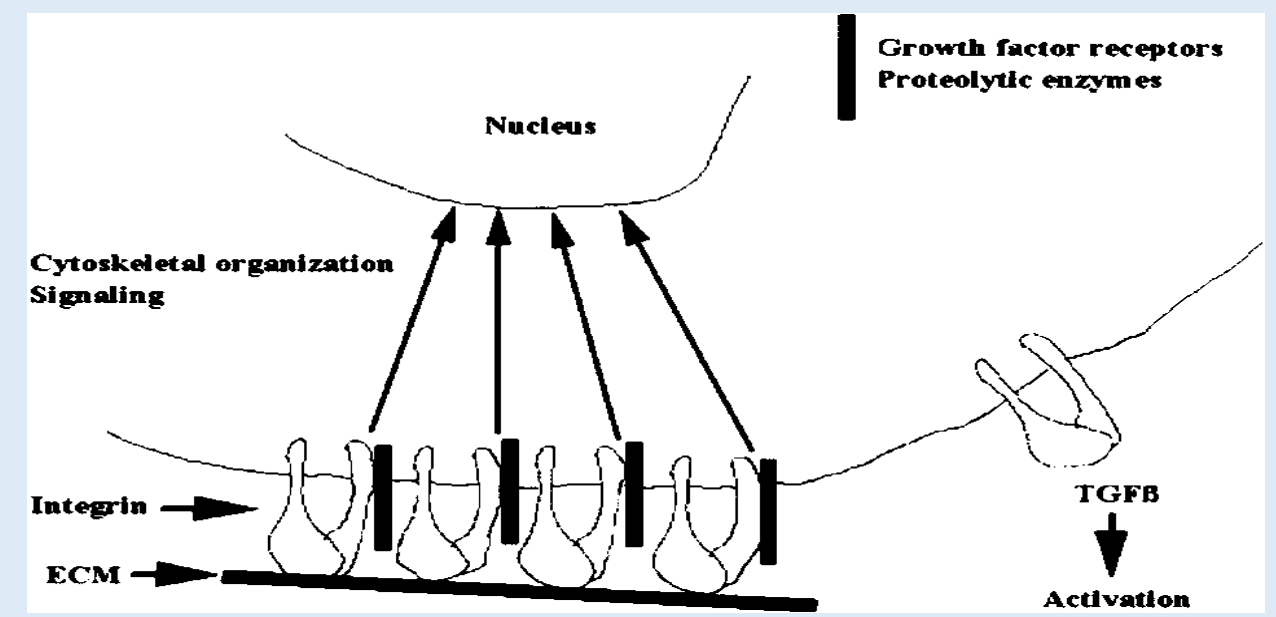

Figure 10: Integrins and cell signalling Integrins mediate cell adhesion to Extracellular

Matrix Proteins (ECM) leading to organization of cytoskeleton and signalling. Integrins collaborate with growth factors. Some integrins can also directly activate growth factors such as TGF- $\beta 1$. Proteolytic enzymes are also found in cell adhesion sites allowing cells to detach and subsequently migrate [37].

Laminin-5 can be proteolytically modified to produce different molecules that function either as a nucleator of the hemidesmosomes (stopping signal) or as a promoter of migration. Laminin-5 seems to be the nucleator of $\alpha 6 \beta 4$ integrin and therefore initiates the basement membrane organization. Fibronectin, tenascin-C play role in keratinocyte sliding. Suprabasal keratinocytes sliding on basal cells after reaching the provisional matrix. The migrating cells stop moving and become basal keratinocytes. Initially, the blood clot contains plasma fibronectin, which is later replaced by cellular fibronectin produced by keratinocytes, fibroblasts and macrophages. Laminin-5 is found in the basement membrane and serves as a component of anchoring filaments that span through the basement membrane. TGF- $\beta$ have a central role in the wound healing process, formed by a family of polypeptides that have multiple regulatory actions in cell growth, differentiation, and developmental processes. The most important role for $\alpha \beta 6$ integrin may be the activation of TGF $\beta 1$, an effect promoting the formation of the connective tissue bridge formation under the epithelium. The first collagen fibrils are laid down under the epithelium in areas where the expression of $\alpha v \beta 6$ is strong and TGF $\beta 1$ is present in active form. TGF $\beta 1$ may also stimulate the proliferation of wounded keratinocytes at the wound margins indirectly. The roles of PDGF, EGF, HGF and others growth factors is well documented in relation with wound healing.

Pericytes that are residents of the surroundings of the vascular endothelium of capillaries and venules are induced to proliferate and migrate into the wound. They take origin from

1. The surrounding connective tissue (migration and differentiation)

2. Pericytes (proliferation, migration)

3. Bone marrow involving systemic control, homing and differentiation 
SPARC also regulate different cellular functions. Thrombospondin plays a role on the activity of TGF- $\beta$, collagen fiber organization and vascularization in the connective tissue.

Myofibroblasts are playing a role in wound contraction and matrix deposition. This is supported by findings that myofibroblasts are typically present in tissues that are under mechanical stress but they are only occasionally found in normal tissue. The differentiation of myofibroblasts occurs between 6 and 15 days after wounding. After 15 days, about $70 \%$ of fibroblasts in granulation tissue express $\alpha$-smooth muscle actin. Differentiation of myofibroblasts coincides with wound contraction. During granulation tissue formation, fibroblasts are stimulated by TGF- $\beta$ deposit new extracellular matrix proteins. Early matrix deposition occurs first at about day 7 after injury in the granulation tissue immediately under the newly formed epithelium. This coincides with the peak in activation of latent TGF- $\beta$ stored in the blood clot provisonal matrix and in the granulation tissue. The induction of epithelial avb6 integrin which regulate the activation of latent TGF- $\beta$. Once activated, TGF- $\beta$ can induce its own production by fibroblasts, a mechanism maintaining high activity of TGF- $\beta$ in the granulation tissue. Saliva provides a unique environment in the mouth conducive for rapid tissue repair. Growth factors found in saliva are synthesized by salivary glands or derived from plasma through gingival crevice. Epithelial and connective tissue cells also produce their own growth factors that act either in a paracrine or autocrine manner. Because many of the growth factors are transported to saliva along with gingival crevicular fluid, it is conceivable that their concentration in gingival tissue is higher than elsewhere in the oral cavity. EGF has a multitude of effects on cell proliferation, migration and on extracellular matrix metabolism. It is obvious that EGF is needed for the maintenance and repair of oral mucosa. Interestingly, salivary EGF also plays a role in the maintenance of gastric and ideal mucosal integrity.

\section{Regeneration of a Whole Tooth}

Trembley in 1744 and later Spallanzani have shown that the tail and limb of salamander regenerate after surgical removal $[41,42]$. The demonstration was completed by Trembley reporting that a bisected hydra may give rise to two completely formed individuals. It comes out from such experiments that the regeneration of part of the body I provide possibility to regenerate a member.

Prominent examples include cnidarians such as hydra, annelids, molluscs, nemertean worms, platyhelminthes such as planarians, and chordates vertebrates [43].

Different mechanisms are involved in the process of dedifferentiation (a cell loses differentiated character and produce a progenitor cell that can divide and produce more differentiated cells), transdifferetiation (involved in the changes of one cell type into others, a process occurring without division), and faithful pattern formation of the regenerated structure.

Adult dividing cells are called neoblasts. They are pluripotent cells. Hydra regeneration is accomplished by three different stem cell populations: 
1. Hydra are cnidarians with a primary body axis containing a hypostome (or head) at one end and a foot at the other. Cell proliferation in the body column continually pushes cells to the poles of the body.

2. The body wall contains two epithelial cell layers, ectodermal and endodermal epithelial cells. Interstitial stem cells exist within the ectodermal epithelial cell layer.

3. The ectodermal and endodermal epithelial cells proliferate continuously to maintain the tissue layers, producing differentiated epithelial cells. A third stem cell type, the multipotent, interstitial stem cell can self-renew and produce neurons, nematocytes, secretory cells, and gametes [44].

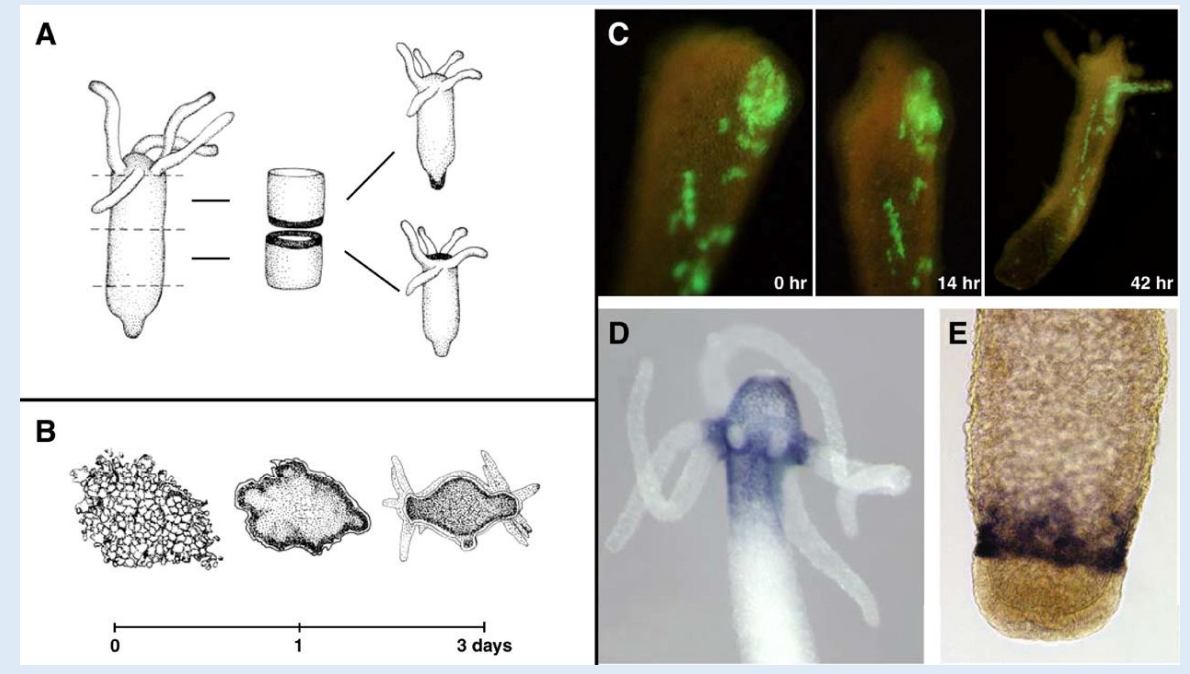

Figure 11: Regeneration of hydra. All epithelial cells in the gastric region are epithelial stem cells with continuous self-renewing capacity and remarkable phenotypic plasticity.

In-vivo observations, therefore, strongly support the previous findings and clearly demonstrate that regeneration in Hydra occurs almost exclusively by morphallaxis. Regeneration in Hydra has also been described at the ultrastructural level as a rapid wound healing process initiated by the endoderm. If, however, we dissociate an intact Hydra into single cells, a perfect polyp will reconstitute itself from the pellet of centrifuged cells within the next few days [45].

Molecular signalling factors including WNTs, BMP/TGF- $\beta$ s, IGFs, and FGFs, have been identified as involved in appendage regeneration based on the inhibition of regeneration upon their inactivation. This was the basis for regenerative therapies (Gerer, 2012). Prominent examples include cnidarians such as Hydra, annelids, molluscs, nemertean worms, platyhelminthes such as planarians, and chordates including vertebrates.

The regenerative capacities of these animals vary. Planarians, for instance, are capable of regenerating missing heads or entire bodies from small fragments, whereas salamanders are capable of re-growing missing limbs. 
Experimentation with regeneration bring us back to the 1700s and the experiments of Abraham Trembley. The potential of single dividing cells was examined. Some cells were observed to have clonogenic potential, that is, the capacity to produce a large number of descendent cells through the process of cell division. Several transplant experiments have been performed that support the idea that a renewing population of dividing cells are the primary contributors to planarian regeneration. Hydra are cnidarians that live as freshwater polyps, with a polarized, primary body axis. The Hydra body axis contains two poles separated by a body column. The oral pole, or head, contains tentacles and hypostome (mouth) and the aboral pole, or foot, contains the basal disc. These animals are composed of two tissue layers, each a single cell thick: an outer layer of ectodermal myoepithelial cells and an inner layer of endodermal myoepithelial cells arranged together in a tube ending in tentacles. Hydra were the first subjects of described regeneration experimentation and are capable of regenerating entire polyps from tiny body fragments. In a remarkable display of body organization capacity, dissociated Hydra cells can even be re-aggregated and produce a new Hydra polyp. The epithelial cells in the Hydra body column continuously proliferate and replace differentiated epithelial cells at the poles of the polyp. In addition to proliferation occurring in the myoepithelial cells, highly proliferative interstitial cells exist within the epithelial cell layers. To investigate the potential of individual interstitial cells, clonal analyses were performed taking advantage of the capacity of Hydra to re-aggregate into a cell suspension. It was shown that interstitial cells are multipotent stem cells that can generate neurons, nematocytes, secretory cells, and gametes, but not the epithelial layer. Cartilage was recognized as one tissue where grafts consisting purely of cartilage cells could be isolated.

The recent advances, in identifying the cell sources for regeneration in several invertebrate and vertebrate model organisms, have revealed a diversity of ways by which injured tissues provide progenitor cells for regeneration. Hydra appears to employ several restricted stem cell pools, whereas planarians utilize a clonogenic, pluripotent stem cell. Among vertebrates, the blastema used for appendage regeneration is a mosaically built structure made up of several distinct, restricted progenitor cell pools that act in concert. Dedifferentiation and stem cell activation both appear to be contributing mechanisms for producing proliferating progenitors for regeneration, whereas regeneration of the lens occurs via transdifferentiation $[44,46]$. These regeneration processses were extentended to dental structures.

\section{Dental Stem Cells (Apexogenesis, Apexification)}

Adult's mesenchymal stem cells display odontogenic potential and they express odontogenic genes such as Pax9, Msx1, Lhx7, DMP1 and DSPP. Stem cells may be isolated from human exfoliated deciduous teeth (SHED) and/or postnatal human stem cells (DPSCs) $[47,48]$. SCAP cells are derived from the apical part of the papilla of growing tooth roots [49-51]. Stem cells slide from the central part of the pulp to the lateral sub-odontoblastic boundaries. They move from the root toward the coronal part of the crown [52]. DPSCs, SHEDs, SCAPs differentiate

Goldberg M | Volume 1; Issue 2 (2020) | JDHOR-1(2)-008 | Review Article

Citation: Goldberg M. Wound Healing and Dental Therapies: Repair and Regeneration. J Dental Health Oral Res. 2020;1(2):1-43.

DOI: http://dx.doi.org/10.46889/JDHOR.2020.1203 
into odontoblasts and adipocytes. Dental Follicle (DFSCs), and Periodontal Ligament-Like of Permanent Tooth (PDLSCs) may also contribute to regenerative medicine [53-56].

The biology of dental stem cells has an important impact in the context of regenerative dentistry [57]. Populations of DPSCs possesses generic Mesenchymal Stem Cells-like properties (MSCs). They were shown to express in vitro osteoblastic, adipogenic, chondrogenic or even neuronal markers. Dental stem cell populations also express different panels of surface markers such as 3G5, STRO-1, CD44, CD106, CD146, CD90 and Sca-1 used to characterize hematopoetic stem cells.

Apexification implies for a necrotic teeth the induction of apical closure. The calcium hydroxide or Mineral Trioxide Aggregate (MTA) give rise to high success rate. However there are risks of reinfection and tooth fracture [58].

\begin{tabular}{|c|c|c|}
\hline $\begin{array}{l}\text { *Stem Cells } \\
\text { Permanently } \\
\text { Present In Adult } \\
\text { Tooth (DPSCs) }\end{array}$ & $\begin{array}{c}{ }^{*} \text { Dental Stem Cell } \\
\text { Properties }>\text { Self-renewal }\end{array}$ & $\begin{array}{l}\text { Signaling Imputs For } \\
\text { Reparative Dentin } \\
\text { Formation }\end{array}$ \\
\hline $\begin{array}{l}\text { *Dental Pulp Stem } \\
\text { Cell (DPSCs). }\end{array}$ & $\begin{array}{l}\text { > They are able to enter in } \\
\text { mitosis in response to } \\
\text { appropriate signals and to } \\
\text { differentiate toward } \\
\text { odonto/osteogenic cells. }\end{array}$ & $\begin{array}{l}\text { *** Tooth injury may promote } \\
\text { stem cell recruitement } \\
\text { > Local secreted factors } \\
\text { >Bioactive extracellular } \\
\text { matrix molecules }\end{array}$ \\
\hline $\begin{array}{l}\text { *Periodontal } \\
\text { Ligament Stem } \\
\text { Cells (PDLSCs) }\end{array}$ & $\begin{array}{l}>\text { Long-term survival and } \\
\text { maintenance of reparative } \\
\text { capacity }\end{array}$ & $>\mathrm{Ca}^{2+}$ release \\
\hline $\begin{array}{l}{ }^{*} \text { Apical Papilla } \\
\text { Stem Cells (SCAPs) }\end{array}$ & $\begin{array}{l}>\text { Distinct subpopulations } \\
\text { expressing markers of } \\
\text { mesenchymal stem cells of } \\
\text { the bone marrow } \\
>\text { Stro-1, CD44, CD106, } \\
\text { 3G5, CD146, CD90, Sca-1 }\end{array}$ & $\begin{array}{l}\text { >Mechanical inputs changes } \\
\text { in matrix elasticity }\end{array}$ \\
\hline $\begin{array}{l}\text { "Stem Cells Present } \\
\text { in Deciduous Tooth } \\
\text { (SHEDs) }\end{array}$ & & $\begin{array}{l}>\text { Diffusible signals emanating } \\
\text { from stromal, inflammatory, } \\
\text { circulating cells. }\end{array}$ \\
\hline
\end{tabular}




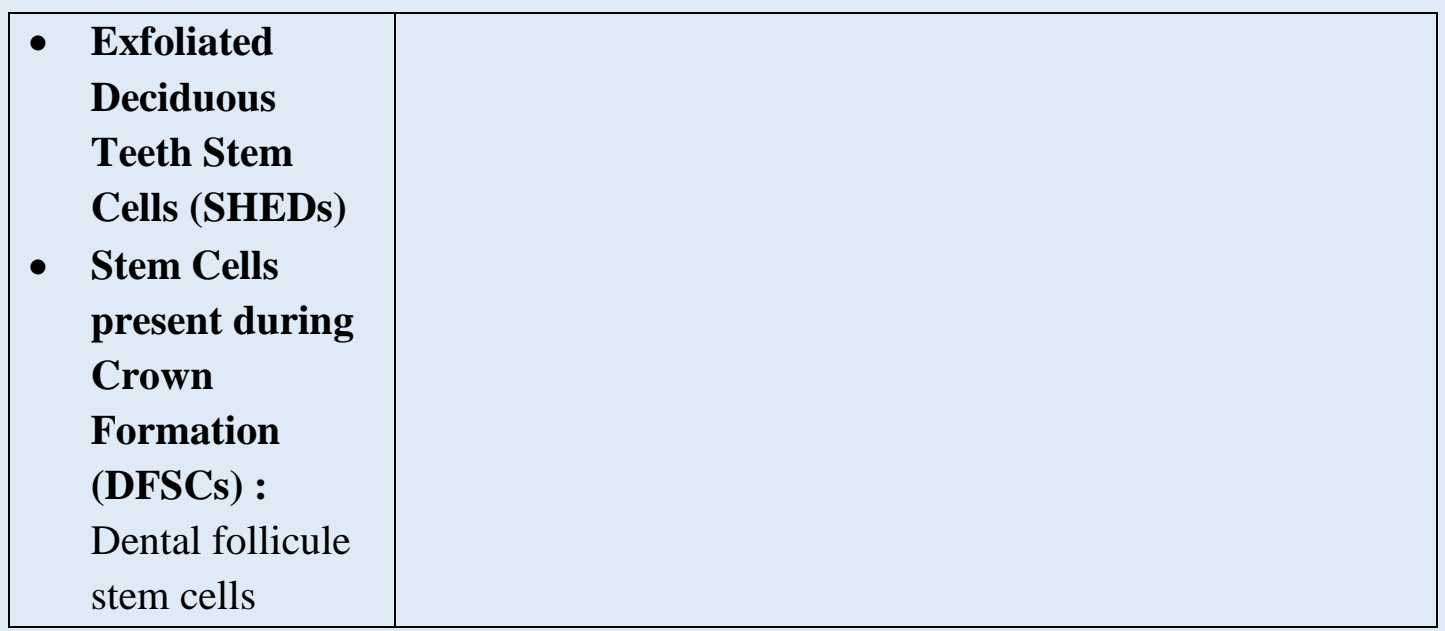

Table 5: Types of dental pulp stem cells and their properties [48-57].

DPSC obtained from the pulp of permanent teeth, may regenerate pulp/dentin; whereas SHED, obtained from exfoliated primary teeth, regenerate only the pulp. SCAP regenerate pulp/dentin in the apical papilla [58].

Following transplantation, DPSCs are clonogenic cells, capable of self-renewal and multilineage differentiation. DPSCs are able to regenerate a dentin-pulp-like complex. Pulp cells express bone markers such as bone sialoprotein, alkaline phosphatase, type I collagen and osteocalcin. Members of the TGF $\beta$ super family and cytokines regulate their differentiation. They are similar to Bone Marrow Stromal Stem Cells (BMSSCs) and display potential to become osteoblasts, chondrocytes, adipocytes, myelo-supportive fibrous-stroma, muscle and neural tissues. They respond to specific environment signals, generating new stem cells.

The phenotypical analysis evidenced that DPSCs were highly positive for CD29, CD44, CD90 and HLA I. They were negative for CD34, CD45, CD71, and HLA II. Postnatal dental pulp contains cells that are clonogenic, highly proliferative, and capable of regenerating a tissue. Hence, these properties define them as stem cells, implicated in regenerative medicine $(59,60)$.

The fractionated DPSC subpopulations exhibit stem cell properties in-vitro:

- High expression of pluripotency markers, Oct3/4, Nanog and Sox2

- High stability in long-term expansion

- Multi-lineage differentiation capacity

- High migratory activity

- High expression of trophic factors that may enhance proliferation, migration, anti-apoptotic and immunomodulatory effects as well as angiogenesis and neurite extension 
DPSC subpopulations have higher angiogenic, neurogenic, and regenerative potential compared with bone marrow stem cells and adipose stem cells, presenting an alternate versatile stem cell source for cellular therapies [61].

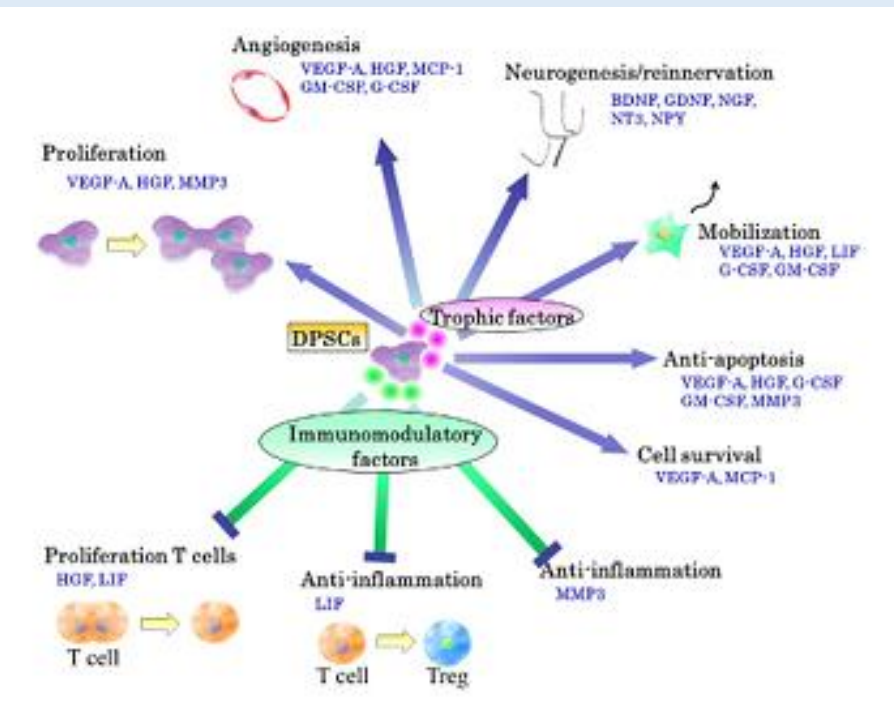

Figure 11: Dental pulp stem cells and regeneration [61].

\section{Pulp Capping (Between Inflammation and Regeneration)}

Indirect or direct pulp capping leads to the formation of reactionary or reparative dentine. Regenerative endodontics restore partially the pulp tissue and its functions beneath a mineralized layer of tertiary dentin. Pulp in the canal space develop revitalization and/or revascularisation. Two strategies have been developped either cell-based or cell-free.

This involves:

1. A critical size defect of dentin and pulp

2. Cell lineage commitment to become odontoblasts

3. Regeneration vs. repair

4. Cell-based pulp regeneration that can be used for clinical application. The cell-based pulp regeneration has been proven to regenerate pulp/dentin.

Co-implantation of endothelial cells with mesenchymal stem cells accelerate dental pulp regeneration/healing in pulpotomized rat molar. In 2 weeks, a dentin bridge is obtained, Bcl-2, chemokine (C-X-C motif) ligand 1, CXC receptor2 and Dentin Sialophosphoprotein (DSPP). Nestin and VEGF (a pro-angiogenic factor) expressions are increased [62]. 


\section{Indirect Pulp Capping}

The stepwise excavation approach intends to change the carious environment and not to remove the carious tissue close to the pulp, because there is a risk of pulp exposure. This approach

- Aims to have a clinical control of the tooth reaction

- Removes the slowly progressing demineralized dentin before filling the cavity with a final restoration

Indirect pulp capping produces tertiary dentin (ortho- or osteo-dentin, also identified as reactionary dentin) beneath a calciotraumatic line or border. This layer is not stained as a dentin containing phosphorylated matrix proteins.

\section{Direct Capping}

Pulp exposure healing produces reparative dentin is influenced by bacterial leakage, the presence of operative debris, inflammation and pulp cell activity, dentin bridge formation, with tunnel defects in the dentin bridges. When a healthy pulp is inadvertently exposed during an operative procedure, a calcium hydroxide $\left[\mathrm{Ca}(\mathrm{OH})_{2}\right]$ is placed over the exposure and dentine formation is stimulated. Direct pulp capping by calcium hydroxide is associated with dentin bridge formation. Direct pulp capping is one of the treatments of an exposed vital pulp. It is limited to partial regeneration to the exposed coronal pulp. Pulpotomy is used to stimulate the maintenance of a vital pulp. It is however mandatory to develop new biologically-based therapeutics that reduce pulp inflammation, promote the continued formation of a renewed dentin-pulp complex, and restore vitality by stimulating the regrowth of pulpal tissue. The odontoblasts-like cells secrete tertiary dentin. Instrumentation beyond the confine of the root canal is susceptible to induce bleeding. The blood clot is a rich source of growth factors. They include PDGF, VEGF, and PDEGF, which stimulate differentiation and maturation of odontoblasts and cementoblasts. 


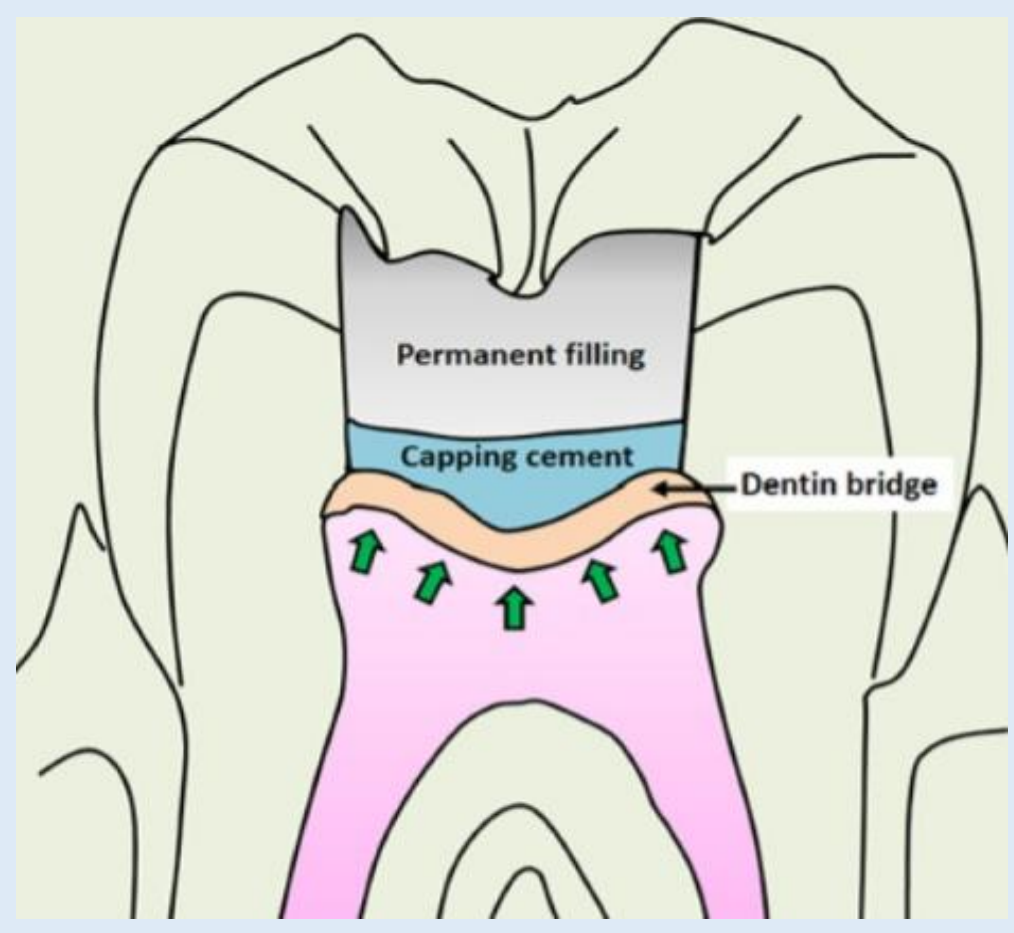

Figure 12: Pulp capping and the formation of reparative dentin bridge [63].

Two other therapies involve more severe destructive pulp lesions. Apexogenesis (root elongation) and apexification (apical closure) result from indirect or direct pulp capping. Apexogenesis is a phenomenon implicating a vital pulp, while apexification is occurring when the pulp is non-vital, infected or not. Apexification enhanced the continued root dentin formation, decreasing the size of the lumen, linked with apical closure and with radicular dental pulp regeneration. Apexogenesis and apexification constitute two alternatives possibilities for endodontic therapies [64,65].

\section{Repair and Regeneration of the Dental Pulp}

After the formation of a blood clot, using matrices, suitable (stem) cells, and signaling molecules to direct tissue events, pulp-like constructs have already been generated. However, a number of challenges still remain for clinical translation of pulp regeneration (resident vs nonresident stem cells, the latter being associated with cell-free approaches), mechanisms of odontoblast differentiation, the pulp environment, dentin pretreatment to release signaling molecules from the dentin, Platelet Rich Plasma (PRP) are a rich source of growth factors and stimulate the tree-dimentional associtation of suitable matrices [66].

A higher number of platelets increase the number of growth factors secreted which contribute to the proliferation of stem cells, inducing healing and promoting the regeneration of the dental pulp. PRP is a concentrated suspension of different growth factors like PDGF, TGF- $\beta$, IGF, VEGF and EGF. These are released via degranulation of alpha granules and stimulate bone and soft-tissue healing [67]. 
The regenerative protocol implies three steps. First disinfection of the teeth with $6 \%$ and $2.5 \%$ $\mathrm{NaOCl}$. Second, in addition, the dressing the root canal with an antibiotic mixture (metronidazolz and cyprofloxacin or calcium hydroxide paste. The double or triple antibiotic paste (cefaclor is added to the double mixture) provide healing of the periapical disease. The third step involves the removal of the canal dressing with a final flush of $17 \%$ EDTA. Inducing a blood clot with a sterile hand file in a fourth step, the blood clot is sealed by a compatible biomaterial. Calcium hydroxide or MTA are well adapted to this final step. Some reports have shown that this method displays a significant increase in root length and an increased root wall thickness. The biodegradable scaffold can be synthetic polymers (e.g. poly (D-L-LactidecoGlycolide) [PLG]) or Poly Glycolic Acid (PGA) or processed biological products (e.g., collagen matrix or gel) [68].

Stem cell niche are still unclear it was found to be localized in the perivascular and perineural sheath regions. STRO-1/CD146/CD44 staining of the periodontal ligament has shown that it is mainly located in the paravascular region, and small clusters of cells are in the extravascular region, suggesting that these are the niches of periodontal ligament stem cells.

The positive markers are: STRO-1, CD13, CD44, CD24, CD29, CD73, CD90, CD105, CD106, CD146, Oct4, Nanog and $\beta 2$ integrin, and the negative markers: CD14, CD34, CD45 and HLA-DR. Side population cells exist in porcine dental pulp exhibiting stem cell properties with self-renewal and multipotency for dentinogenesis, chondrogenesis, adipogenesis and neurogenesis. DPSCs, SHED and SCAP are potentially suitable cell sources for pulp/dentin regeneration because they are derived from pulp tissue or the precursor of pulp. DPSCs and SCAP are known to form a pulp-dentin complex when transplanted into immunocompromised mice, whereas SHED forms mineralized tissue.

Pulp cells (DPSC) may be used for partial regeneration of the pulp. If complete regeneration of the lost tissue is desired, application of recombinant GF to the injured site enhance the regeneration of dentin.

Among the growth factor that were identified, the Bone Morphogenetic Proteins (BMPs) were isolated from adult bone matrix in mammals by extracting demineralized bone matrix. BMPs are related to the superfamily of TGF $\beta$ group. Pulp-derived mesenchymal cells differentiate into dentin-forming pre-odontoblasts. TGF $\beta$ stimulate odontoblasts differentiation. TGF- $\beta 1$ stimulates odontoblastic differentiation, including the expression of dentin sialoprotein (DSP) and Dentin Matrix Protein (DMP-1). Chemotactic properties attract the stem/progenitor cells to the site of injury in the tooth.

Vascular Endothelial Growth Factor (VEGF) promote angiogenesis/vasculogenesis. It is a potent endothelial cell mitogen. VEGF is produced by keratinocytes, macrophages, mast cells, smooth muscle cells and several type of tumors. It influence chemotaxis. VEGF is potentially beneficial for pulp regeneration. 
The strategy used combine bFGF, VEGF, PDGF, NGF and BMP7. It provide a simple and economical approach for pulp regeneration [69].

There is a need for scaffolds for dental pulp and periodontal regeneration to promote apexification (after disinfection treatment) with antibiotics and calcium hydroxide (or MTA), followed by root canal sealing inducing dental wall thickening and root end closure. The 3 major events form the biological basis for tissue engineering. This encompassnamely stem cells, bioactive signalling molecules and scaffolds. [70,71].

Scaffolds can be easily injected in the desired site. They favor stem cell transplantation or serve as delivery vehicles for bioactive factors. Puramatrix ${ }^{\mathrm{TM}}$, a self-assembling peptide hydrogel mixed with SHED, generated a pulp-like tissue with odontoblasts capable of producing new tubular dentin. Moreover, the engineered pulp showed similar cellularity and vascularization when compared to human pulps. Multidomain Peptides (MDP) aggregate and appear as short sequences of amino acids that self-assemble to form fibers in an aqueous solution. MDPs display the cell adhesion motif Arginine-Glycine-Aspartic Acid (RGD), Matrix Metalloproteinase (MMP)-cleavable site, and heparin-binding domains. They allowed growth factors conjugation and assisted in its slow release.

A well-known hydrogel (i.e., Gelatin methacrylate, GelMA) was recently investigated for dental pulp regeneration. GelMA is composed of denatured collagen and retains RGD adhesive domains and MMP-sensitive sites. GelMA enhances cell binding and matrix degradation. Furthermore, it is suitable for cell encapsulation and easily tunable by varying the concentrations of GelMA and photoinitiators.

A novel, star-shaped block copolymer, poly (L-lactic acid)-block-poly-(L-lysine), was seen to be capable of self-assembling into nanofibrous microspheres (NF-SMS). The NF-SMS microspheres supported DPSC proliferation and demonstrated DSPP expression in-vitro.

The regeneration of dental-pulp-like tissue based on the intracanal delivery of FGF2 and/or VEGF without stem cell transplantation, leads to pulp regeneration. A re-cellularized and revascularized connective tissue, integrated with the native dentinal wall in root canals was observed following in-vitro implantation of endodontically-treated human teeth.

Histological findings demonstrated that periapical tissue laceration leads to vascularized tissue formation within the root canal system. This method have laid the groundwork for dental pulp tissue engineering. This implies that regeneration of pulp and dentin will have clinical utility in endodontics [72].

Nör and Cucco were considering the complete pulp regeneration [73]. A functional dentin/pulp complex would enable the completion of root development and thickening of the dentinal walls. The recruitment of apical cells toward the root canal and/or transplantation of stem cells was successful using a tissue engineering-based approach. 
Bioactive nanofibrous antibiotic-containing scaffolds were used for regenerative endodontics. Metronidazole or cyproflofloxacin was mixed with a polydioxanone (PDS) polymer [70]. The polymer-based antibiotic-containing scaffolds could function as a biologically safe antimicrobial drug delivery system for regenerative endodontics.

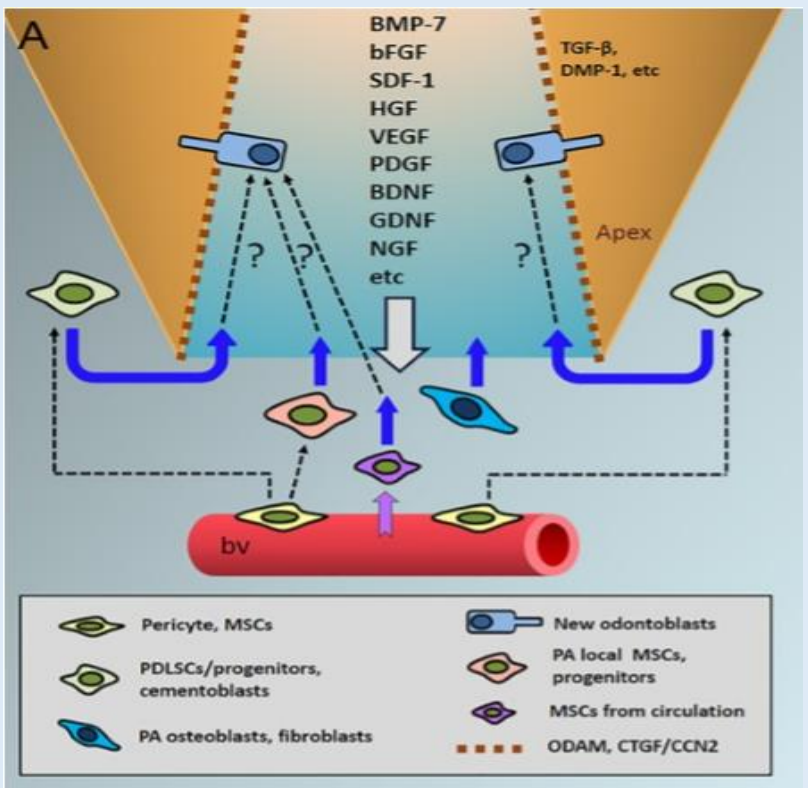

Figure 13: Pulp regeneration and growth factors [61].

\section{Periodontal Tissue Regeneration (Bone, Cementum and Periodontal Ligament)}

Bone-marrow stem cells promote periodontal regeneration. Using Adipose-Derived Stem Cells (ASCs), periodontal regeneration was also promoted when the cells were used at passage twice, and mixed with Platelet-Rich Plasma (PRP) implanted in the periodontal defect, which was seen to heal and regenerate [74].

After implantation of porcine enamel matrix (amelogenin fraction) in defects prepared in the buccal alveolar bone plate, the exposed periodontal ligament and cementum of a buccal dehiscence model were restored in monkey. After 8 weeks using PGA (Propylene Glycol Alginate) as vehicle, and combined with the acidic extract enamel matrix preparation resulted a complete regeneration of acellular cementum and periodontal tissues (periodontal ligament and bone) [75].

An organized cementum-periodontal ligament-like complex has been developped, using scaffold-free tissue engineering that displays self-assembly and forms a periodontal ligament, identified by the presence of ligament-associated protein-1 and periostin and cementum [76]. Short term application of a combination of PSGF and IGF-1 accelerates the regeneration of periodontal tissues [77]. 
Guided Tissue Regeneration (GTR) utilize barrier membranes to guide the specialized cellular components to participate in the regeneration process. The GTR concept is based on the fact that the periodontal ligament contains all the cells necessary for the formation of bone, cementum and periodontal ligament [78].

Non-resorbable materials include expanded Poly Tetrafluoroethylene (ePTFE, Goretex ${ }^{\mathrm{TM}}$ ) membranes made from ePTFE have traditionally been used as guided tissue barrier membranes. However, it is possible that these membranes could also be used to nurture specific cells that are expanded ex-vivo and then delivered to a defect site.

Porous Ceramic Scaffolds: Several porous ceramic scaffolds have been examined for their utilization as cell delivery materials. In general, many of these materials have been developed and investigated, however making impossible the neovascularization. Hydroxapatite has a good biocompatibility of these hybrid materials, but they are also lacking interconnectivity. Biodegradable porous ceramics such as porous ceramic mixtures of beta-TCP and hydroxyapatite or beta-TCP and polymers, appear to be good vehicles for cell delivery and the studies published are showing good tissue formation associated with the implanted cells.

Resorbable Materials: These materials include materials such as polyesters of naturally occurring alpha-hydroxy acids, amino-acid based polymers, alginate and natural materials such as collagen and reconstituted extracellular matrix proteins. The alpha-hydroxy acid polymers include Poly Glycolic Acid (PGA), Poly (L-lactic Acid) [PLLA] and copolymers of Poly (lactic-co-glycolic Acid) [PLGA]. These materials can be engineered in order to degrade over long or short periods of time depending on the need. These materials can also be easily manufactured into preformed sizes and shapes as dictated by the site of the defect and its anatomy.

Alginate beads may incorporate cells, entrapped within an alginate droplet transformed in a rigid bead by gelation in a divalent cation solution. Amino acid based polymers have been used for cell seeding. The processing make the material similar to natural amino acid containing matrix molecules such as collagens and elastin.

Scaffolds may be derived from Natural Products: They include hyaluronate, chitosan, and collagen scaffolds. Synthetic hydrogels such as Poly Ethylene Glycol (PEG) and Poly Ethylene Oxide (PEO) are also showing considerable promise for use as a three-dimensional scaffold for cell delivery. They are also showing considerable promise for use as a three-dimensional scaffold for cell delivery.

Extracellular matrix scaffolds (extracts or derivatives) have been developed, such as Matrigel ${ }^{\mathrm{TM}}$ (BD Biosciences, USA) Dermagraft ${ }^{\mathrm{TM}}$ (Advanced Tissue Sciences Inc, La Jolla, CA, USA), Apligraf $^{\mathrm{TM}}$ (Organogenesis Inc, Canton, Massachusetts) and Epidex ${ }^{\mathrm{TM}}$ (Modex Therapeutiques SA, Lausanne, Switzerland). All of them allow the incorporation of ex-vivo expanded cells. Nanostructured fibrous scaffold reminiscent of extracellular matrix can be constructed using the $\mathrm{pH}$-induced self-assembly of a peptide-amphiphile. After cross-linking, the fibres are able Goldberg M | Volume 1; Issue 2 (2020) | JDHOR-1(2)-008 | Review Article 
to direct mineralization of hydroxyapatite to form a composite material in which the crystallographic c-axes of hydroxyapatite crystals are aligned with the long axes of the collagen fibrils $[79,80]$.

\section{Cementum Regeneration}

Three cementum types differ in their structure. It is related to the presence/absence of cells and orientation of collagen fibers. The Acellular Afibrillar Cementum (AAC) covers teeth along the cemento-enamel junction. It consists of mineralized matrix, but lacks collagen fibrils and embedded cells. Acellular Extrinsic Fiber Cementum (AEFC) function is the primary attachment. It covers cervical and middle portions of the roots, and is confined to the coronal half of the root. It consists of a dense fringe of collagenous fibers implanted into dentinal matrix and perpendicular to the root surface. Cellular Intrinsic Fiber Cementum (CIFC) is found on dentin. The organic matrix of cementum is composed primarily of collagens. Type I collagen, which plays structural as well as morphogenic roles and provides scaffolding for mineral crystals, is the major species. It accounts for $90 \%$ of all collagens. The type III collagen, which coats type I collagen fibrils, makes up 5\%. Cementum contains two major non-collagenous proteins, Bone Sialoprotein (BSP) and Osteopontin (OPN). These proteins, which are prominently expressed in acellular extrinsic fiber cementum and acellular afibrillar cementum, remain bound to the collagen matrix. They possess cell attachment properties through the ArgGly-Asp (RGD) sequence. Several polypeptide growth factors with ability to promote the proliferation and differentiation of putative cement oblasts sequestered in the cementum matrix. This cementum includes BMP-2, -3 , and 4, PDGF, $a-$ and b- FGFs, TGF- $\beta$ and IGF-1. IGF-I isoform is referred to a Cementum Growth Factor (CGF). The second molecule specific for this tissue is a collagenous protein referred as Cementum Attachment Protein (CAP).

Periodontal Regeneration: Viable cementoblasts and/or periodontal ligament cells near the cementum appear to play a critical role in the regeneration of the tooth attachment apparatus. Activation of the canonical Wnt signalling pathway induces new cellular cementum regeneration and the formation of a well-organized periodontal ligament. It increases mineralization, alkaline phosphatase activity and the expression of the bone and cementum markers (osteocalcin, osteopontin, Cementum Protein 1(CEMP1) and CAP. Inhibition of sclerostin promotes bone formation via activation of canonical Wnt signalling. Inhibition of GSK3 $\beta$ enhances canonical Wnt signalling and consequently activates the Wnt signalling. Both bone and cementum healing result of Wnt inhibition [81].

Several integrins as well as their natural ligands (such as collagens, BSP, OPN, CAP) are expressed by cementoblastic cells, implying that they may be important regulators of cementogenesis. Integrins may be directly involved in some aspects of cementum formation. The increaeased number of active adhesive integrin ligands on mineralized surfaces enhances the formation of cementum by committed cementogenic cells $[35,36,76]$. 
Combined PDGF and dexametasone induce also regeneration of the periodontium in monkey [82]. Another promising group of polypeptide growth factors is the Bone Morphogenetic Proteins (BMP), which offer good potential for stimulating bone and cementum regeneration [83]. Enamel matrix derivative (Emdogain) contribute actively to periodontal regeneration [84].

\section{Regeneration of the Periodontal Ligament}

Periodontal diseases are infectious diseases characterized by progressive destruction of the periodontium (tooth-supporting tissue), including the Periodontal Ligament (PDL), cementum, alveolar bone, and gingiva. The progenitor cells residing within the PDL (Periodontal Ligament progenitor, PDLPs) are named PDLSC. PDLSCs can be further characterized by the cell surface expression of CD29, CD44, STRO-1, STRO-4, CD146, CD73, CD90, CD105 and CD166 and the lack of expression of endothelial (CD31), haematopoietic (CD14, CD34, CD45, and CD79a), and helper immune antigens (HLA-DR, CD40, CD54, CD80, and CD86). Exploring how ncRNAs participate in the osteogenic differentiation of PDLSCs help to elucidate the mechanisms of the osteogenic differentiation of PDLSCs and shed light on the potential of stem cell transplantation for periodontium regeneration. Due to their capability to osteogenic differentiation, PDLSCs show effective potential in the clinical application of periodontium repair and regeneration.

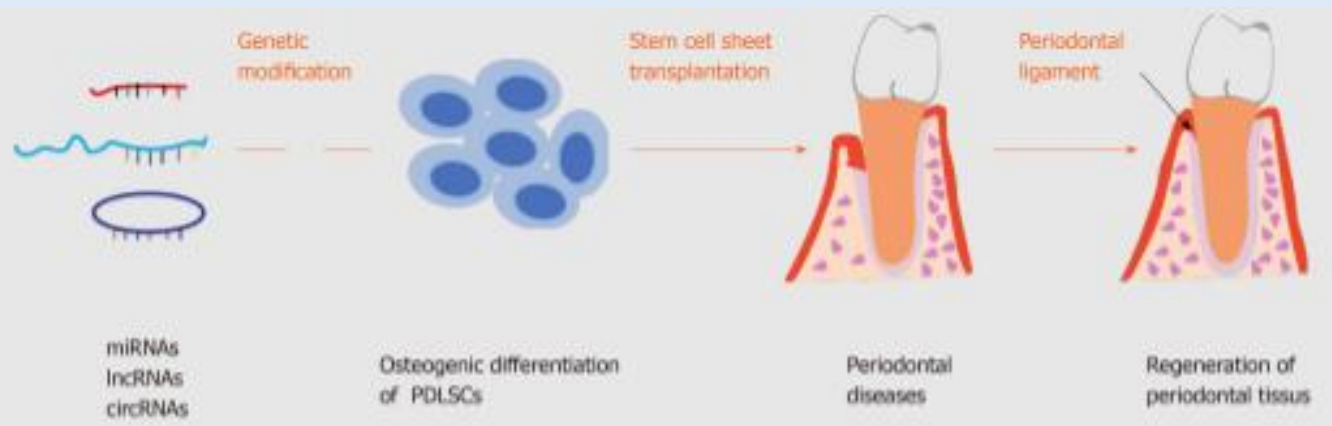

Figure 14: Regeneration of periodontal tissus by periodontal ligament stem cells transplantation therapy. Osteogenic differentiation of the cells into the bone defects may regenerate the periodontal ligament. mRNAs microTNA, IncRNAs Long non-coding RNAs, circRNAs Circular RNAs ; PDLSC Periodontal ligament stem cells [85].

Advanced biomaterials for periodontal regeneration. They are grouped into two classes: nonresorbable and resorbable. Non-resorbable membranes (polytetrafluoroethylene) involve repair of the lesion, but the removal of the membrane constitute another difficulty and needs a second intervention [71]. 
Resorbable membranes are based on polyesters and/or their copolymers. Collagen membranes derived from the Extracellular Matrix (ECM) have become important alternatives to their synthetic counterparts, due to their excellent cell biocompatibility.

In conclusions regarding periodontal tissue engineering, regenerative strategies with membranes associated or not with grafting materials have been used with distinct levels of clinical success. With the aging population, it is crucial to find a tissueengineering/regenerative medicine approach that allows the fabrication of scaffolds that can ultimately guide reliable and predictable regeneration of multiple periodontal tissues [86].

\section{Conclusion}

The healing of dental lesions, or the regeneration of either the dental pulp or the periodontal tissues (bone, gingival tissue, cementum, and the periodontal ligament) pave the way for the future of endodontic and periodontal therapies.

\section{References}

1. Sherratt JA, Dallon JC. Theoretical models of wound healing: past successes and future challenges. Comptes Rendus Biologies. 2002;325(5):557-64.

2. Velnar T, Bailey T, Smrkolj V. The wound healing process: an overview of the cellular and molecular mechanisms. J Int Med Res. 2009;37(5):1528-42.

3. Reinke JM, Sorg H. Wound repair and regeneration. Euro Surg Res. 2012;49(1):35-43.

4. Tracy LE, Minasian RA, Caterson EJ. Extracellular matrix and dermal fibroblast function in the healing wound. Adv in Wound Care. 2016;5(3):119-36.

5. Zomer HD, Trentin AG. Skin wound healing in humans and mice: Challenges in translational research. J Dermatological Sci. 2018;90(1):3-12.

6. Martin P, Leibovich SJ. Inflammatory cells during wound repair: the good, the bad and the ugly. Trends in Cell Biology. 2005;15(11):599-607.

7. Dissanayaka WL, Hargreaves KM, Jin L, Samaranayake LP, Zhang C. The interplay of dental pulp stem cells and endothelial cells in an injectable peptide hydrogel on angiogenesis and pulp regeneration in vivo. Tissue Engineering Part A. 2015;21(3-4):550-63.

8. Oberyszyn TM. Inflammation and wound healing. Front Biosci. 2007;12(8):2993-9.

9. Eming SA, Krieg T, Davidson JM. Inflammation in wound repair: molecular and cellular mechanisms. J Investigative Dermatol. 2007;127(3):514-25.

10. Ennis WJ, Sui A, Bartholomew A. Stem cells and healing: impact on inflammation. Adv in wound care. 2013;2(7):369-78. 
11. Singer NG, Caplan AI. Mesenchymal stem cells: mechanisms of inflammation. Annu Rev Pathol. 2011;6:457-78.

12. Nakashima M, Iohara K, Murakami M, Nakamura H, Sato Y, Ariji Y, et al. Pulp regeneration by transplantation of dental pulp stem cells in pulpitis: a pilot clinical study. Stem Cell Res Ther. 2017;8(1):61.

13. Whitby DJ, Ferguson MW. Immunohistochemical localization of growth factors in fetal wound healing. Developmental Biol. 1991;147(1):207-15.

14. Pastore S, Mascia F, Mariani V, Girolomoni G. The epidermal growth factor receptor system in skin repair and inflammation. J Investigative Dermatol. 2008;128(6):1365-74.

15. Malinda KM, Kleinman HK, Sidhu GS, Mani H, Banaudha K, Maheshwari RK, et al. Thymosin $\beta 4$ accelerates wound healing. J Investigative Dermatol. 1999;113(3):364-8.

16. Reed JC. Bcl-2 and the regulation of programmed cell death. J Cell Biol. 1994;124(1-2):1-6.

17. Kerr JF, Wylie AH, Currie AR. Apoptosis: a basic biological phenomenon with wide-ranging implications in tissue kinetics. Br J Cancer. 1972;26:239-57.

18. Greenhalgh DG. The role of apoptosis in wound healing. Int J Biochem Cell Biol. 1998;30(9):1019-30.

19. St-Arnaud R, Demay MB. Vitamin D Biology. In Pediatric Bone 2012 ;8 :163-187.

20. Eming SA, Werner S, Bugnon P, Wickenhauser C, Siewe L, Utermöhlen O, et al. Accelerated wound closure in mice deficient for interleukin-10. Am J Pathology. 2007;170(1):188-202.

21. Stojadinovic O, Brem H, Vouthounis C, Lee B, Fallon J, Stallcup M, et al. Molecular pathogenesis of chronic wounds: the role of $\beta$-catenin and c-myc in the inhibition of epithelialization and wound healing. Am J Pathology. 2005;167(1):59-69.

22. Goldberg M, Njeh A, Uzunoglu E. Is pulp inflammation a prerequisite for pulp healing and regeneration?. Mediators of inflammation. 2015;2015:347649.

23. Hilario E, Cañavate ML, Lacalle J, Alonso-Alconada D, Lara-Celador I, Alvarez-Granda L, et al. Cell death. A comprehensive approximation. Delayed cell death. Microscopy: Science, Technology, Applications and Education. Badajoz: Formatex Research Centre. 2010:1025-32.

24. Guo SA, DiPietro LA. Factors affecting wound healing. J Dent Res. 2010;89(3):219-29.

25. George Broughton, Janis JE, Attinger CE. Wound healing: an overview. Plast Reconstr Surg. 2006;117(7S):1e-S.

26. Krawczyk WS. A pattern of epidermal cell migration during wound healing. J Cell Biol. 1971;49(2):24763.

27. Werner S, Grose R. Regulation of wound healing by growth factors and cytokines. Physiol Rev. 2003;83(3):835-70.

28. Barrientos S, Stojadinovic O, Golinko MS, Brem H, Tomic-Canic M. Growth factors and cytokines in wound healing. Wound Repair and Regeneration. 2008;16(5):585-601.

29. Schultz GS, Wysocki A. Interactions between extracellular matrix and growth factors in wound healing. Wound Repair and Regeneration. 2009;17(2):153-62. 
30. Gill SE, Parks WC. Metalloproteinases and their inhibitors: regulators of wound healing. Int J Biochem Cell Biol. 2008;40(6-7):1334-47.

31. Hattori N, Mochizuki S, Kishi K, Nakajima T, Takaishi H, D'Armiento J, et al. MMP-13 plays a role in keratinocyte migration, angiogenesis, and contraction in mouse skin wound healing. Am J Pathol. 2009;175(2):533-46.

32. Dimitriou R, Jones E, McGonagle D, Giannoudis PV. Bone regeneration: current concepts and future directions. BMC Med. 2011;9(1):66.

33. Koenig BB, Cook JS, Wolsing DH, Ting J, Tiesman JP, Correa PE, et al. Characterization and cloning of a receptor for BMP-2 and BMP-4 from NIH 3T3 cells. Molecular and Cellular Biology. 1994;14(9):5961-74.

34. Petite H, Viateau V, Bensaid W, Meunier A, de Pollak C, Bourguignon M, et al. Tissue-engineered bone regeneration. Nature Biotechno. 2000;18(9):959-63.

35. Grzesik WJ, Narayanan AS. Cementum and periodontal wound healing and regeneration. Crit Rev Oral Biol Med. 2002;13(6):474-84.

36. Grzesik WJ, Cheng H, Oh JS, Kuznetsov SA, Mankani MH, Uzawa K, et al. Cementum-forming cells are phenotypically distinct from bone-forming cells. J Bone Mineral Res. 2000;15(1):52-9.

37. HAeKKINEN LA, UITTO VJ, Larjava H. Cell biology of gingival wound healing. Periodontol. 2000;24(1):127-52.

38. Armitage GC. Development of a classification system for periodontal diseases and conditions. Annals of Periodontol. 1999;4(1):1-6.

39. Highfield J. Diagnosis and classification of periodontal disease. Aus Dental J. 2009;54:S11-26.

40. Caley MP, Martins VL, O'Toole EA. Metalloproteinases and wound healing. Advances in Wound Care. 2015;4(4):225-34.

41. Trembley A. Mémoires pour servir à l'histoire d'un genre de polypes d'eau douce, à bras en forme de cornes. Chez J and H Verbeek. 1744.

42. Spallanzani, L. Prodromo di un opera da impnmersi sopra /a riproduzioni animali, Nella Stamperia di Giovanni Montanari, Modena. An essay on animal reproductions. London. 1769.

43. Gerer A. The Hydra model- a model for what? International. J Developmental Biology. 2012;56:437-45.

44. Tanaka EM, Reddien PW. The cellular basis for animal regeneration. Developmental Cell. 2011;21(1):172-85.

45. Bosch TC. Why polyps regenerate and we don't: towards a cellular and molecular framework for Hydra regeneration. Developmental Biol. 2007;303(2):421-33.

46. Tanaka EM. Cell differentiation and cell fate during urodele tail and limb regeneration. Curr Opin Genetics Develop. 2003;13(5):497-501.

47. Gronthos S, Mankani M, Brahim J, Robey PG, Shi S. Postnatal human dental pulp stem cells (DPSCs) in-vitro and in-vivo. Proc Natl Acad Sci. 2000;97(25):13625-30. 
48. Miura M, Gronthos S, Zhao M, Lu B, Fisher LW, Robey PG, et al. SHED: stem cells from human exfoliated deciduous teeth. Proc Natl Acad Sci. 2003;100(10):5807-12.

49. Sonoyama W, Liu Y, Fang D, Yamaza T, Seo BM, Zhang C, et al. Mesenchymal stem cell-mediated functional tooth regeneration in swine. PloS One. 2006;1(1):79.

50. Sonoyama W, Liu Y, Yamaza T, Tuan RS, Wang S, Shi S, et al. Characterization of the apical papilla and its residing stem cells from human immature permanent teeth: a pilot study. J Endod. 2008;34(2):166-71.

51. Huang GT, Sonoyama W, Liu Y, Liu H, Wang S, Shi S. The hidden treasure in apical papilla: the potential role in pulp/dentin regeneration and bioroot engineering. J Endod. 2008;34(6):645-51.

52. Hirata A, Dimitrova-Nakov S, Djole SX, Ardila H, Baudry A, Kellermann O, et al. Plithotaxis, a collective cell migration, regulates the sliding of proliferating pulp cells located in the apical niche. Connect Tissue Res. 2014;55(1):68-72.

53. Seo BM, Miura M, Gronthos S, Bartold PM, Batouli S, Brahim J, et al. Investigation of multipotent postnatal stem cells from human periodontal ligament. The Lancet. 2004;364(9429):149-55.

54. Morsczeck C, Götz W, Schierholz J, Zeilhofer F, Kühn U, Möhl C, et al. Isolation of precursor cells (PCs) from human dental follicle of wisdom teeth. Matrix Biol. 2005;24(2):155-65.

55. Honda MJ, Imaizumi M, Tsuchiya S, Morsczeck C. Dental follicle stem cells and tissue engineering. J Oral Sci. 2010;52(4):541-52.

56. Harichane Y, Hirata A, Dimitrova-Nakov S, Granja I, Goldberg A, Kellermann O, et al. Pulpal progenitors and dentin repair. Adv Dent Res. 2011;23(3):307-12.

57. Dimitrova-Nakov S, Harichane Y, Goldberg M, Kellermann O. Dental stem cells: Progress and perspectives. World J Stomatol. 2013;2(3):35-9.

58. Rafter M. Apexification: a review. Dental Traumatol. 2005;21(1):1-8.

59. Huang GT. Dental pulp and dentin tissue engineering and regeneration-advancement and challenge. Front Biosci. 2011;3:788.

60. Goldberg M. Stem Cells: Tools for dental tissues regeneration. J Dent Health Oral Disord Ther. 2017;6(4):00208.

61. Nakashima M, Ioara K, Murakami M. Dental pulp stem cells and regeneration. Endodontic Topics. 2013;28(1):38-50.

62. Sueyama Y, Kaneko T, Ito T, Kaneko R, Okiji T. Implantation of endothelial cells with mesenchymal stem cells accelerates dental pulp tissue regeneration/healing in pulpotomized rat molars. J Endod. 2017;43(6):943-8.

63. Huang GJ, Garcia-Godoy F. Missing concepts in de novo pulp regeneration. J Dental Res. 2014;93(8):717-24.

64. Friedlander LT, Cullinan MP, Love RM. Dental stem cells and their potential role in apexogenesis and apexification. Int Endod J. 2009;42(11):955-62.

65. Shabahang S. Treatment options: apexogenesis and apexification. Pediatric Dent. 2013;35(2):125-8. 
66. Schmalz G, Smith AJ. Pulp development, repair, and regeneration: challenges of the transition from traditional dentistry to biologically based therapies. J Endod. 2014;40(4):S2-5.

67. Casagrande L, Cordeiro MM, Nör SA, Nör JE. Dental pulp stem cells in regenerative dentistry. Odontol. 2011;99(1):1-7.

68. Huang GT. Pulp and dentin tissue engineering and regeneration: current progress. Reg Med. 2009;4(5):697-707.

69. Nosrat A, Kim JR, Verma P, Chand PS. Tissue engineering considerations in dental pulp regeneration. Iranian Endod J. 2014;9(1):30-40.

70. Bottino MC, Kamocki K, Yassen GH, Platt JA, Vail MM, Ehrlich Y, et al. Bioactive nanofibrous scaffolds for regenerative endodontics. J Dent Res. 2013;92(11):963-9.

71. Bottino MC, Pankajakshan D, Nör JE. Advanced scaffolds for dental pulp and periodontal regeneration. Dental Clin. 2017;61(4):689-711.

72. Nakashima M, Akamine A. The application of tissue engineering to regeneration of pulp and dentin in endodontics. J Endod. 2005;31(10):711-8.

73. Nör JE, Cucco C. The future: stem cells and biological approaches for pulp regeneration. InPediatric Endod. 2016:149-161.

74. Tobita M, Uysal AC, Ogawa R, Hyakusoku H, Mizuno H. Periodontal tissue regeneration with adiposederived stem cells. Tissue Engineering Part A. 2008;14(6):945-53.

75. Hommarsfrom L, HeijI K, Gestrelius S. Periodontal regeneration in o buooal dehiscence modei in monkeys after application of enamei matrix profeins. J Clin Periodontoi. 1997;24:669-77.

76. Lynch SE, Castilla GR, Williams RC, Kiritsy CP, Howell TH, Reddy MS, et al. The effects of shortterm application of a combination of platelet-derived and insulin-like growth factors on periodontal wound healing. J Periodontol. 1991;62(7):458-67.

77. Basu A, Rothermund K, Ahmed MN, Syed-Picard FN. Self-assembly of an organized cementumperiodontal ligament-like complex using scaffold-free tissue engineering. Frontiers in Physiol. 2019;10:422.

78. Karring T, Nyman S, Gottlow JA, Laurell L. Development of the biological concept of guided tissue regeneration-animal and human studies. Periodontol. 1993;1(1):26-35.

79. Nyman S, Gottlow J, Karring T. The regenerative potential of the periodontal ligament. An experimental study in the monkey. J Clin Periodontol. 1982;9:257-65.

80. Bartold PM, Xiao Y, Lyngstaadas SP, Paine ML, Snead ML. Principles and applications of cell delivery systems for periodontal regeneration. Periodontol 2000. 2006;41(1):123-35.

81. Han P, Ivanovski S, Crawford R, Xiao Y. Activation of the canonical Wnt signaling pathway induces cementum regeneration. J Bone and Mineral Res. 2015;30(7):1160-74.

82. Rutherford RB, Ryan ME, Kennedy JE, Tucker MM, Charette MF. Platelet-derived growth factor and dexamethasone combined with a collagen matrix induce regeneration of the periodontium in monkeys. $\mathbf{J}$ Clin Periodontol. 1993;20(7):537-44. 
83. Ripamonti U, Reddi AH. Periodontal regeneration: potential role of bone morphogenetic proteins. J Periodont Res. 1994;29(4):225-35.

84. Haase HR, Bartold PM. Enamel matrix derivative induces matrix synthesis by cultured human periodontal fibroblast cells. J Periodontol. 2001;72(3):341-8.

85. Qiu W, Wu BL, Fang FC. Overview of noncoding RNAs involved in the osteogenic differentiation of periodontal ligament stem cells. World J Stem Cells. 2020;12(4):251.

86. Lyngstadaas SP, Lundberg E, Ekdahl H, Andersson C, Gestrelius S. Autocrine growth factors in human periodontal ligament cells cultured on enamel matrix derivative. J Clin Periodontol. 2001;28(2):181-8. 